\title{
Status Quo of PVT Characterization
}

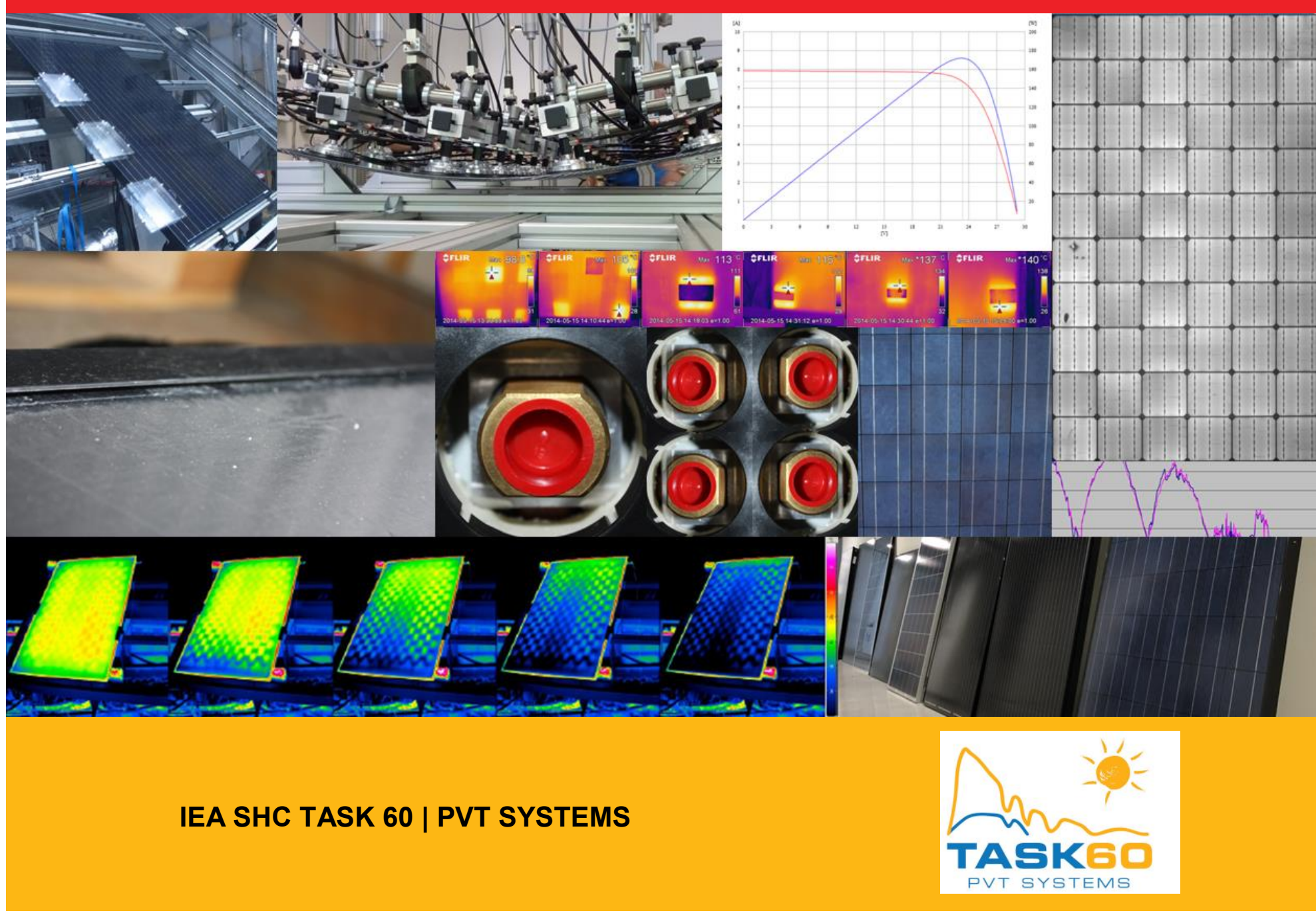




\title{
Status Quo of PVT Characterization
}

\author{
SHC Task 60 - Report B1
}

\author{
Main author: \\ K. Kramer (korbinian.kramer@ise.fraunhofer.de), Fraunhofer ISE, Freiburg, Germany
}

\section{With contributions by:}

N. Amrizal, Indonesia; J.-B. Beyssac (baptiste.beyssac@univ-perp.fr), University of Perpignan, France; $L$. Brottier (laetitia.brottier@dualsun.fr), Dual Sun, France; A. Gagliano (antonio.gagliano@dieei.unict.it), University of Catania, Italy; S. Fischer, University of Stuttgart, Germany; M. Herrando (mherrando@unizar.es), University of Zaragoza, Spain; D. Jonas (danny.jonas@aut.uni-saarland.de), Saarland University, Germany; C. de Keizer (corry.dekeizer@tno.nl), TNO, The Netherlands; M. Lämmle (manuel.laemmle@ise.fraunhofer.de), Fraunhofer ISE, Germany; M. Pellegrini (marco.pellegrini3@unibo.it), University of Bologna, Italy; N. Pokorny (nikola.pokorny@cvut.cz), Czech Technical University in Prague, Czech Republic; M. Proell (Markus.Proell@zae-bayern.de), ZAE Bayern, Germany; C. Schmidt, Germany; G. Tina (giuseppe.tina@dieei.unict.it), University of Catania, Italy; XingXing Zhang (xza@du.se), Dalarna University, Sweden

October $1^{\text {st }}, 2020$

Report number, DOI 10.18777/ieashc-task60-2020-0004

The contents of this report do not necessarily reflect the viewpoints or policies of the International Energy Agency (IEA) or its member countries, the IEA Solar Heating and Cooling Technology Collaboration Programme (SHC TCP) members or the participating researchers. 
PVT technology is an essential part of a sustainable and future-oriented power supply. Previous, its market potential still remains unexploited.

Previous Task 60 reports have presented the current market situation of different PVT systems as well as the subsidy practices in regard to PVT technology [IEA SHC Task 60].

In order to achieve a sustainable PVT market development, reliability of product quality is another key factor, and it can only be achieved by establishing functioning standards.

This report therefore aims at displaying the Status Quo of PVT Characterization in order to support PVT technology in its further development and applications. The report is hence of interest for researchers as well as public and private sector stakeholders.

A key finding is that the reliability and durability of PVT modules are especially challenged at elevated temperatures and higher humidity loads. The test methods available from the IEC and ISO standards are covering the specifics of PV and ST module's, most of which are similar for PVT modules, too.

Yet, the PVT specific load collectives and the operating conditions arising from the system integration of PVT are only partially covered in the set of existing standards (e.g. stagnation temperature approval, mechanical load resistance).

Moreover, the warranties of existing PV modules set equally high consumer expectations in regard to PVT collectors, but it is not self-evident that PVT technology can comply with these expectations.

Therefore, further investigations will be necessary in order to achieve a sustainable market development.

We hope this report will contribute to this development by illustrating the state of the art and by pointing out where more research is needed. 
1 Applications of PVT collectors …............................................................ 1

2 Status quo of performance characterization ................................................... 4

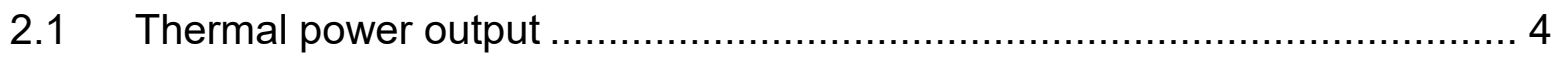

2.1.1 Operating Above Ambient Temperature ………................................. 4

2.1.2 Operating Below Ambient Temperature ............................................... 19

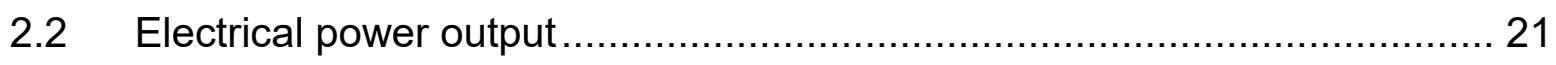

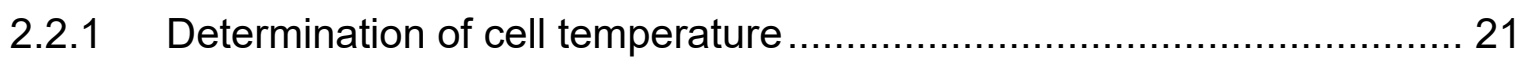

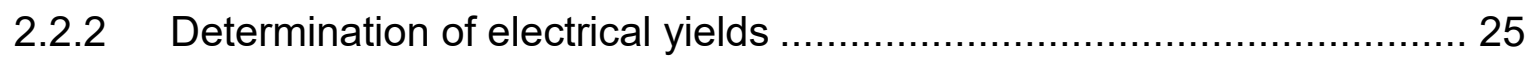

3 Discussion of methodological approaches …….......................................... 31

3.1 Impact on market development ....................................................... 31

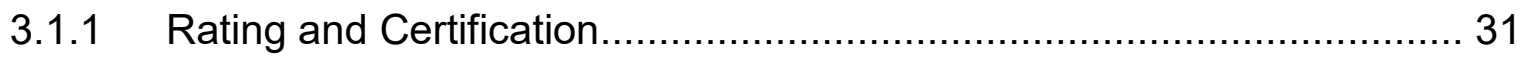

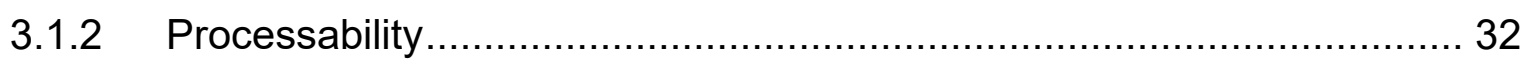

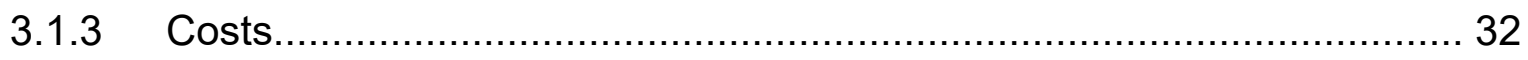

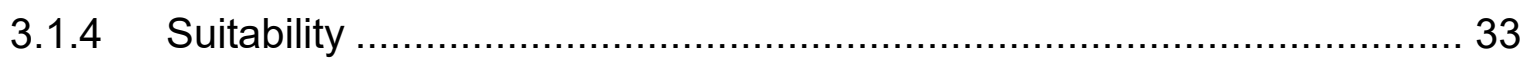

3.2 Precision of equation model and accuracy ........................................... 33

4 List of research questions...................................................................... 38

5 Function Test, Reliability, Serviceability, Durability and Accelerated Aging Test 39

5.1 Certification, Market Access and Legally Mandatory Test......................... 39

5.2 Warranty and Differentiation of PVT products ........................................ 43

6 Conclusion on Reliability Testing Methodology ......................................... 44

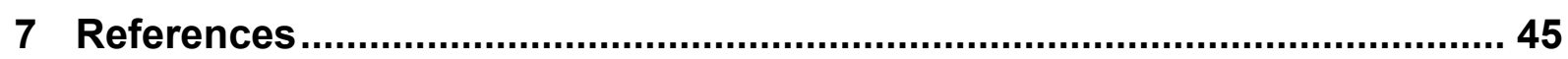




\section{Applications of PVT collectors}

PVT technology is used in various applications. Therefore different operating conditions are found and thus the collector designs reflect this in various forms. The following report takes these two aspects into account. First it is structured along electrical and thermal energy output. Second it reflects the input of the participants in Task 60 for different applications. Therefore, the report is not covering very sophisticated solutions for all possible application scenarios. The report follows the delegates present at the task meetings and their mail contributions. Nevertheless, the authors tried to contribute with listings of open questions to provide an overview of the status quo.

On many topics more details can be found in complementary reading, in the reports cites and links to relevant work published.

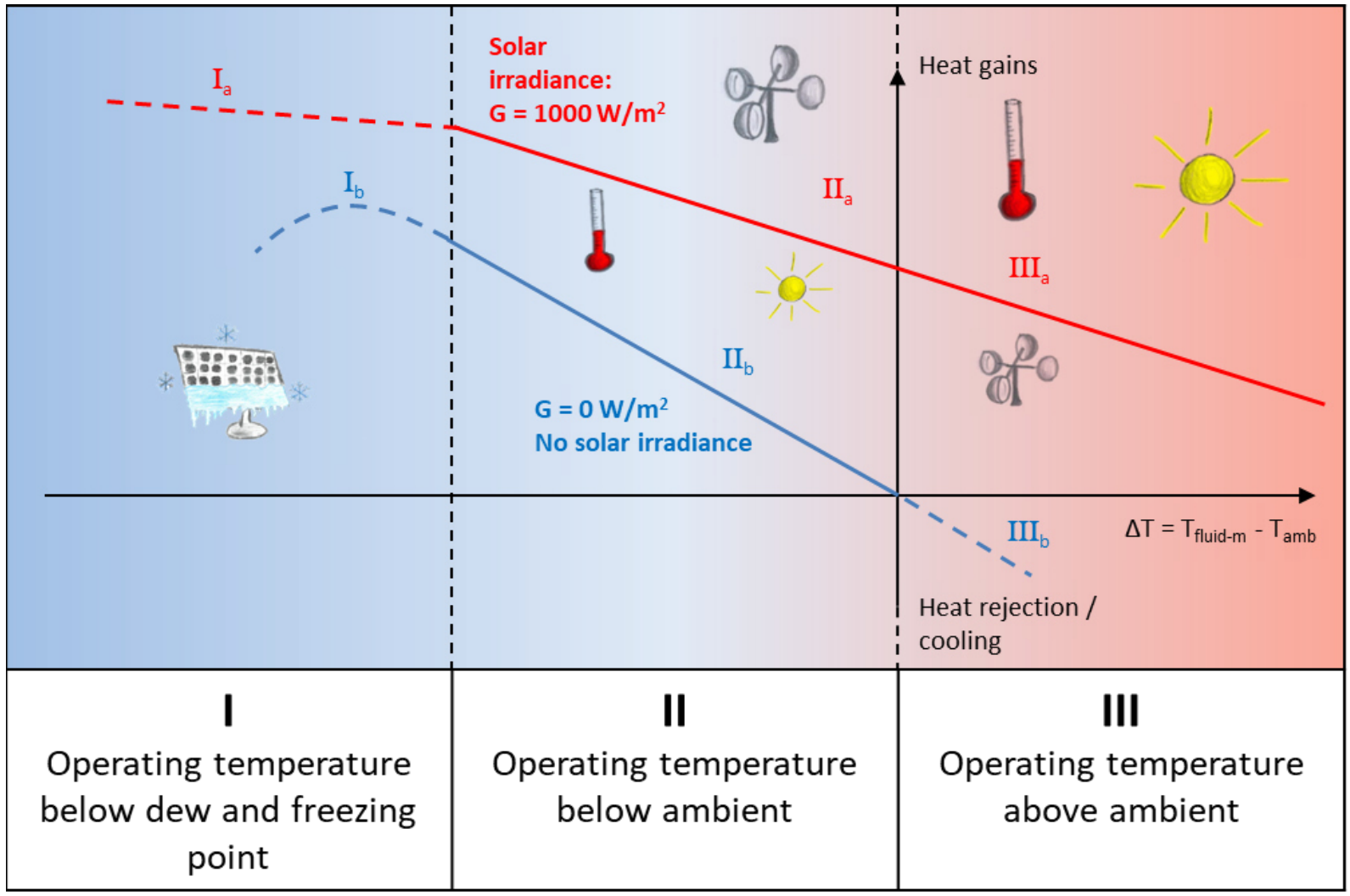

Figure 1: Factors influencing the efficiency of a PVT collector for different operating conditions.

One of the most influential parameters for the system performance and the technical characterization of a system is the operation temperature [M. Lämmle et al. 2017]. Both the thermal and the electrical power outputs are influenced although to different degrees (more details can be found in: [M. Rosa-Clot and G. Tina 2017], [A. Louwen et al. 2017]). Figure 2 shows the temperature influence in thermal and electrical gains per square meter of collector aperture area calculated using the software "ScenoCalc" for the city of Würzburg, Germany (Central Europe) [M. Lämmle 2018]. One can see that it is essential for the technical characterization of a PVT collector to represent this effect. 


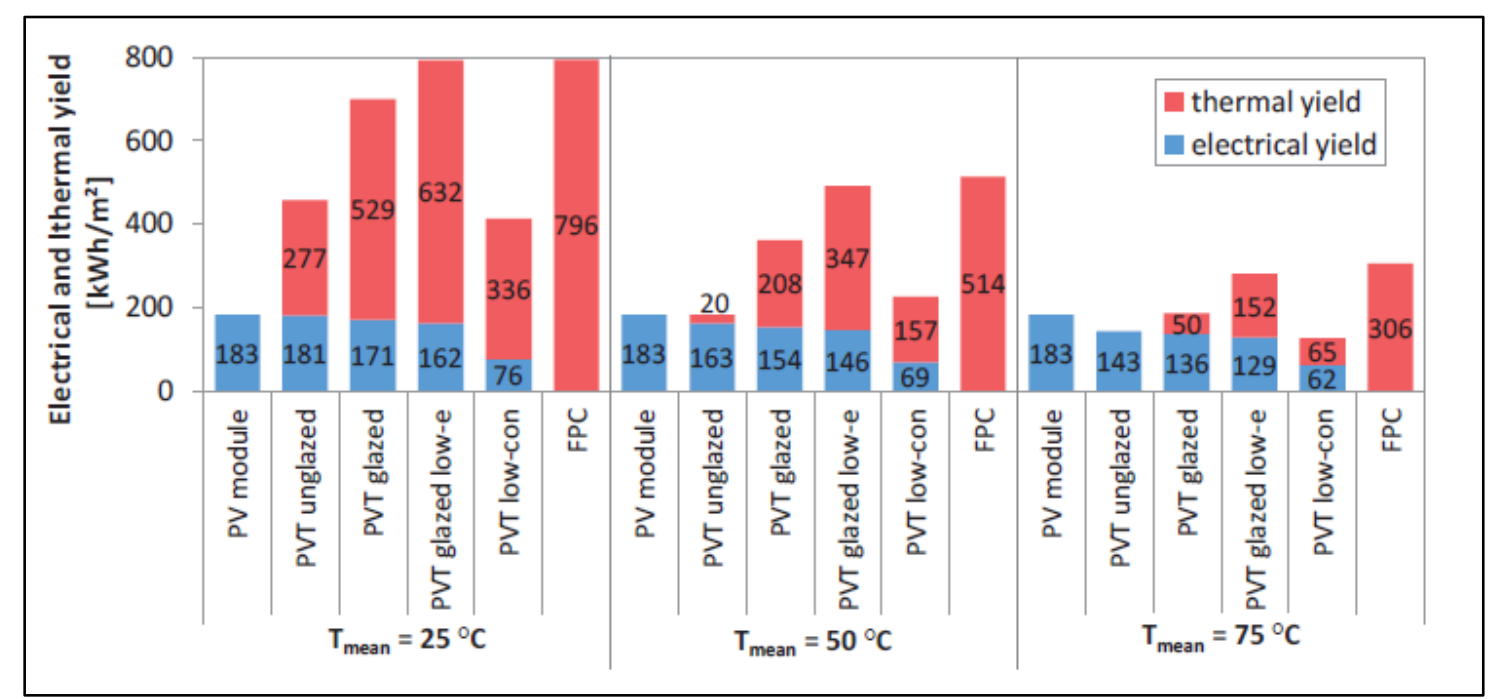

Figure 2: Assessment of total energy yields for different collector technologies at the location of Würzburg [M. Lämmle 2018]

Because of the very diverse technical performances of every collector design at various temperatures, different applications must be targeted.

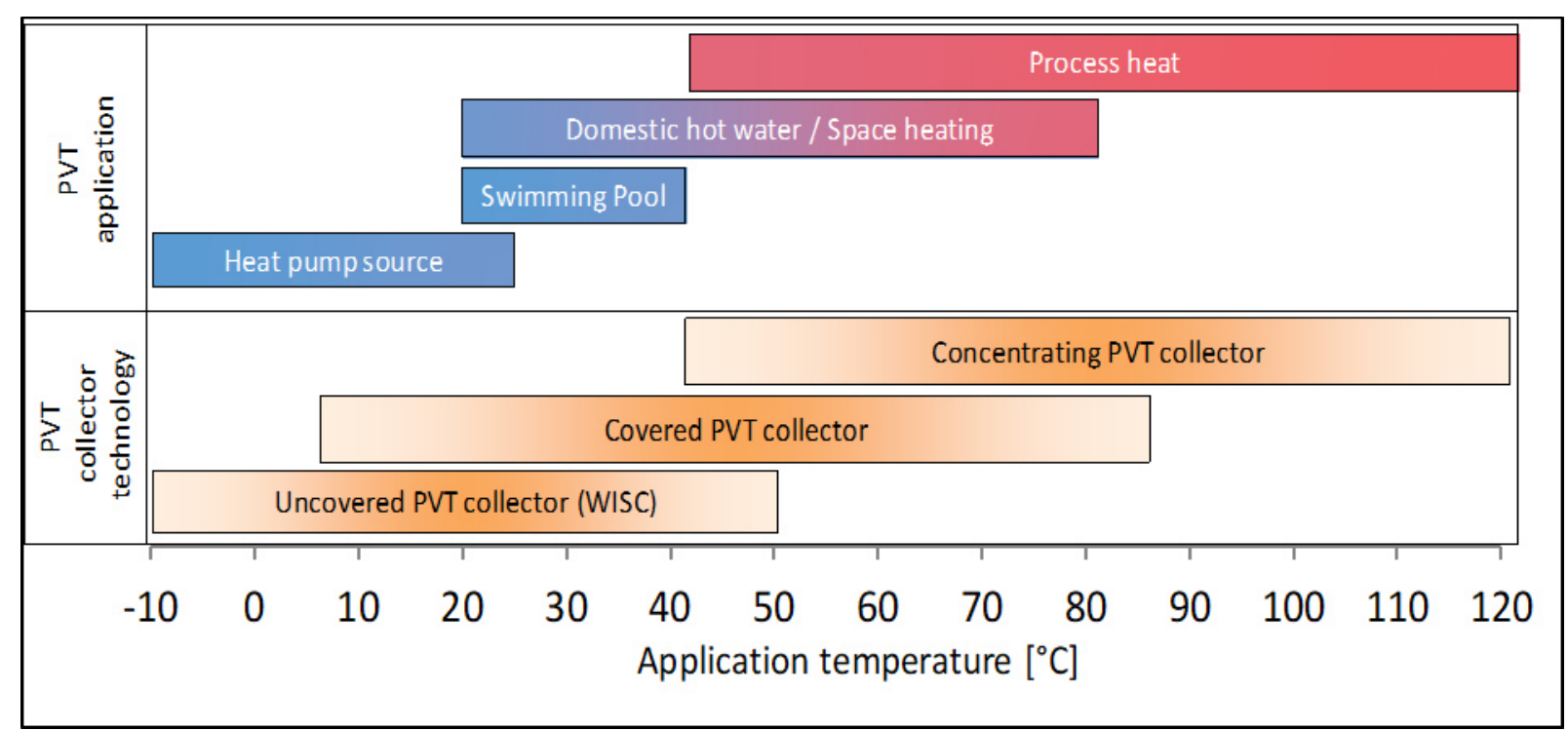

Figure 3: Recommended applications for PVT collectors over the operating temperature ranges.

Several market analyses performed over the last years have shown the market shares of all different PVT collector designs and in different application fields ([D. Zenhäusern et al. 2017], [C. de Keizer et al. 2017], [M. Adam et al. 2015]). Within Subtask A of the IEA SHC Task 60, the statistical data of installed square meters of different PVT collector designs have been gathered and published in Solar Heat Worldwide for the very first time in 2019 [W. Weiss and M. Spörk-Dür 2019, 2020]. The market boundaries (e.g. certification rules, standards for testing, subsidy schemes) as well as the technical constraints (e.g. temperature limitations imposed by standard PV Materials) and economic conditions (e.g. development costs, time to market) are currently more favourable for one specific PVT design, that is the 
uncovered PVT collector (international standards name it more adequately: WISC Wind and Infrared Sensitive Collector). This being said, the focus for the market uptake and penetration should be on providing rules for technical characterization of all PVT collectors since gaps in public knowledge have been identified, probably due to small a market during the past years for PVT technologies.

Not only at collector level, the whole system design is also relevant for the operation modes of the collector. Thus, it is relevant to understand the different configurations in which a PVT collector field can be installed when incorporated into a system. In order to facilitate the access to this complex information, a tool developed in IEA SHC Task 44 is very useful, the so called "square view" representation of a solar installation. To avoid repetition and to keep this report short, we recommend to refer to the related published report of Subtask D of IEA SHC Task 44.

Task 60 could not handle however all possible applications of PVT technologies. There are applications which have rather specific technical characterization parameters and could not be handled within the framework of this Task 60, because the technical characteristics at the system level are more important than those at the collector level e.g.:

- PVT collector as a direct evaporator of refrigerant or coolant in the source loop of a heat pump [addresed in IEA SHC Task 44].

- PVT collector as a source for thermal driven cooling process using absorption chillers [adressed in IEA SHC Task 53].

The present report gathers the status quo of technical characterization approaches from different sources. The level of details and explanations is therefore not perfectly homogeneous. The authors tried to be precise and clear in the description of the different approaches and derive conclusions from that sorting and analysis. Based on this, the report derives recommendations for the handling of PVT collectors with regard to technical characterization. It is meant to be a source of know-how and input to the relevant industry, technical committees of standardization organizations and certification bodies as well as to interested parties. 


\section{Status quo of performance characterization}

\subsection{Thermal power output}

Currently a specific norm for testing PVT collectors as such is not available. In the course of the Task 60 (2018-2020) and partly induced by the work of task members the following status quo was achieved:

1. The thermal performance of PVT collectors can be tested according to the standard ISO 9806:2017 [ISO 2017].

2. A Solar Keymark certification of PVT collectors is possible on that basis with application of specific rules for PVT collectors as described in Annex P5.1 of the Solar Keymark Scheme Rules [ESTIF/SKN]. According to this thermal performance test of PVT collectors shall take place with synchronous thermal and electrical generation under maximum power point (MPP) conditions. Since the thermal and electrical yields are interdependent and some operation conditions of the thermal performance are not covered by the existing standards it is interesting to investigate more in those operating conditions, aiming to 1) compare PVT collectors with each other, and 2) compare PVT collectors with PV and solar thermal collectors on a more sophisticated basis.

\subsubsection{Operating Above Ambient Temperature}

(Based on contribution by M. Pellegrini, C. de Keizer, L. Brottier, N. Pokorny, M. Lämmle, D. Jonas, J.-B. Beyssac, K. Kramer)

Different models used to evaluate the thermal power output of a PVT module at above ambient conditions are described below.

\subsubsection{Models based on the Standard ISO 9806}

\subsection{Using direct ISO equations}

I. According to ISO 9806:2013 standard for liquid heating collectors, depending upon the test method, the extracted thermal power $\dot{Q}_{t h}[$ in W] is modelled as below:

Under steady-state test (SST) method for glazed liquid heating collectors:

$\dot{Q}_{t h}=A_{G} G\left[\eta_{0, h e m}-a_{1}\left(\left(\vartheta_{m}-\vartheta_{a}\right) / G\right)-a_{2} G\left(\left(\vartheta_{m}-\vartheta_{a}\right) / G\right)^{2}\right]$

With this model, a good correspondence between measured and computed thermal energy can be observed on days with uninterrupted solar radiation, wherein measured thermal yield can be slightly lower than the theoretical one, probably due to the incident angle variation influence that was not considered, in particular in the morning and in the evening [A. Bianchini et al. 2017]. The PVT system was tested with a $\vartheta_{\mathrm{a}}$ in a range $20-35^{\circ} \mathrm{C}$ and with a $\vartheta_{\mathrm{m}}$ between $35-50^{\circ} \mathrm{C}$. So, an overestimation of solar thermal production can be expected through the application of the above equation during sunny days. When solar radiation $G$ varies during the day, more 
relevant discrepancies can be found between measured and theoretical daily energy yield. Bianchini et al. found that in most of the cases ( $80 \%$ of monitored days), the measured thermal energy yield was lower than the theoretical one (with a minimum of $58 \%$ ), but there were also days ( $20 \%$ of monitored days) where measured thermal energy yield resulted higher than the theoretical one (with a maximum of $130 \%$ ). The cause of these variations can be found in the thermal inertia of the PVT system, which is not considered. So, depending on how $\vartheta_{m}$ varies throughout the day, depending on the environmental conditions and/or operating conditions, the measured thermal power $P_{t h}$ produced by the PVT plant can be relatively lower or higher than the theoretical thermal power. On the other hand, if the whole monitoring period considered by Bianchini et al. is evaluated, the theoretical mean daily thermal energy production results as $11 \%$ higher than the measured one. Therefore, the equation can be applied with good approximation to predict PVT thermal yield in the medium-long term or for installations characterized by daily stable environmental conditions, since the presence of daily unstable conditions increases the errors.

Under steady-state test method for unglazed liquid heating collectors [ISO 2013]:

$\dot{Q}_{t h}=A_{G} G^{\prime \prime}\left[\eta_{0, h e m}\left(1-b_{u} u\right)-\left(b_{1}+b_{2} u\right)\left(\left(\vartheta_{m}-\vartheta_{a}\right) / G^{\prime \prime}\right)\right]$

Where,

$G^{\prime \prime}=G+(\varepsilon / \alpha)\left(E_{L}-\sigma T_{a}^{4}\right)$

In some cases, it is suggested to use wind speed, $u$ of $1.5 \mathrm{~m} / \mathrm{s}$ for better accuracy (according to DualSun).

Under quasi dynamic test (QDT) method [ISO 2013]:

$\dot{Q}_{t h}=A_{G}\left[\eta_{0, b} K_{b}\left(\theta_{L}, \theta_{T}\right) G_{b}+\eta_{0, b} K_{d} G_{d}-a_{1}\left(\vartheta_{m}-\vartheta_{a}\right)-a_{2}\left(\vartheta_{m}-\vartheta_{a}\right)^{2}-a_{3} u\left(\vartheta_{m}-\vartheta_{a}\right)\right.$
$\left.+a_{4}\left(E_{L}-\sigma T_{a}^{4}\right)-a_{5}\left(d \vartheta_{m} / d t\right)-a_{6} u G\right]$

The above QDT model is implemented in TRNSYS Type 832 [M. Haller et al. 2013] and offers an additional term for the consideration of latent (condensation + sublimation) heat gains ( $\dot{q}_{\text {lat }}$ ). For the calculation of condensation gains, two models are implemented which are based on the methods of [B. Perers 2010] and [E. Bertram et al. 2010]. In addition, a frosting mode has been added to both models for the possibility of consideration of sublimation. However, it is expressly noted that there is no validation of this feature and no subsequent melting or increased heat transfer resistance is calculated.

The quasi-dynamic test method offers a much more complete characterization of the collector and a much wider range of collectors can be tested within the same method, compared to the steady-state test methods. Less restrictions in the test requirements makes it easier to find periods for outdoor testing [S. Fischer et al. 2004]. 
II. According to ISO 9806:2017 [ISO 2017] standard for liquid heating collectors, depending upon the test method, the extracted thermal power $\dot{Q}_{t h}[$ in W] is modelled as follows:

Under steady-state test (SST) method:

$$
\begin{gathered}
\dot{Q}_{t h}=A_{G}\left[\eta_{0, h e m} G_{h e m}-a_{1}\left(\vartheta_{m}-\vartheta_{a}\right)-a_{2}\left(\vartheta_{m}-\vartheta_{a}\right)^{2}-a_{3} u^{\prime}\left(\vartheta_{m}-\vartheta_{a}\right)+a_{4}\left(E_{L}-\sigma T_{a}^{4}\right)\right. \\
\left.-a_{6} u^{\prime} G_{\text {hem }}-a_{7} u^{\prime}\left(E_{L}-\sigma T_{a}^{4}\right)-a_{8}\left(\vartheta_{m}-\vartheta_{a}\right)^{4}\right]
\end{gathered}
$$

Under quasi dynamic test (QDT) method (errata: $\mathrm{G}$ equals $\mathrm{G}_{\mathrm{hem}}$ ):

$$
\begin{gathered}
\dot{Q}_{t h}=A_{G}\left[\eta_{0, b} K_{b}\left(\theta_{L}, \theta_{T}\right) G_{b}+\eta_{0, b} K_{d} G_{d}-a_{1}\left(\vartheta_{m}-\vartheta_{a}\right)-a_{2}\left(\vartheta_{m}-\vartheta_{a}\right)^{2}-a_{3} u^{\prime}\left(\vartheta_{m}-\vartheta_{a}\right)\right. \\
+a_{4}\left(E_{L}-\sigma T_{a}^{4}\right)-a_{5}\left(d \vartheta_{m} / d t\right)-a_{6} u^{\prime} G_{h e m}-a_{7} u^{\prime}\left(E_{L}-\sigma T_{a}^{4}\right) \\
\left.-a_{8}\left(\vartheta_{m}-\vartheta_{a}\right)^{4}\right]
\end{gathered}
$$

As the electrical mode of operation has a significant impact on the thermal efficiency, the thermal performance coefficients for the thermal power output calculation of the PVT collector should be determined in MPP mode [M. Lämmle et al. 2017].

It is important to note that in the 2017 version, the two steady state equations are combined to only one equation which can be used for both glazed and unglazed (as already mentioned, referred to as WISC in ISO 9806:2017) collectors under certain conditions. In the updated version, hemispherical solar irradiance $(G)$ is used instead of net irradiance (G"). The surrounding air speed $(u)$ is replaced [M. Lämmle et al. 2017] by reduced surrounding air speed ( $\left.u^{\prime}\right)$ where $u^{\prime}=u-3(\mathrm{~m} / \mathrm{s})$. In order to maintain consistency in results, it is suggested to use the updated standard ISO 9806:2017.

Where,

$\begin{array}{lll}A_{G} & \text { Gross area of collector as defined in the ISO } 9488 & \mathrm{~m}^{2} \\ a_{1} & \text { Heat loss coefficient } & \mathrm{W} /\left(\mathrm{m}^{2} \mathrm{~K}\right) \\ a_{2} & \text { Temperature dependence of the heat loss coefficient } & \mathrm{W} /\left(\mathrm{m}^{2} \mathrm{~K}^{2}\right) \\ a_{3} & \text { Wind speed dependence of the heat loss coefficient } & \mathrm{J} /\left(\mathrm{m}^{3} \mathrm{~K}\right) \\ a_{4} & \text { Sky temperature dependence of the heat loss coefficient } & -- \\ a_{5} & \text { Effective thermal capacity } & \mathrm{J} /\left(\mathrm{m}^{2} \mathrm{~K}\right) \\ a_{6} & \text { Wind speed dependence of the zero loss efficiency } & \mathrm{s} / \mathrm{m} \\ a_{7} & \text { Wind speed dependence of IR radiation exchange } & \mathrm{W} /\left(\mathrm{m}^{2} \mathrm{~K}^{4}\right) \\ a_{8} & \text { Radiation losses } & \mathrm{W} /\left(\mathrm{m}^{2} \mathrm{~K}^{4}\right) \\ b_{1} & \text { heat loss coefficient at }\left(\vartheta_{m}-\vartheta_{a}\right)=0 & \mathrm{~W} /\left(\mathrm{m}^{2} \mathrm{~K}\right) \\ b_{2} & \text { wind dependence of the heat loss coefficient } & \mathrm{Ws} /\left(\mathrm{m}^{3} \mathrm{~K}\right) \\ b_{u} & \text { collector efficiency coefficient }(\text { wind dependence) } & \mathrm{s} / \mathrm{m} \\ E_{L} & \text { Longwave irradiance (wavelength, } \lambda>3 \mu \mathrm{m}) & \mathrm{W} / \mathrm{m}^{2}\end{array}$




\begin{tabular}{lll}
$G$ & Hemispherical solar irradiance & $\mathrm{W} / \mathrm{m}^{2}$ \\
$G_{h e m}$ & Hemispherical solar irradiance & $\mathrm{W} / \mathrm{m}^{2}$ \\
$G_{b}$ & Direct solar irradiance (beam irradiance) & $\mathrm{W} / \mathrm{m}^{2}$ \\
$G_{d}$ & Diffuse solar irradiance & $\mathrm{W} / \mathrm{m}^{2}$ \\
$K_{b}\left(\theta_{L}, \theta_{T}\right)$ & Incidence angle modifier for direct solar irradiance & -- \\
$K_{d}$ & Incidence angle modifier for diffuse solar radiation & -- \\
$\dot{Q}_{t h}$ & Thermal power output & $\mathrm{W}$ \\
$t$ & Time & $\mathrm{s}$ \\
$T_{a}$ & Ambient temperature & $\mathrm{K}$ \\
$u$ & Surrounding air speed & $\mathrm{m} / \mathrm{s}$ \\
$u^{\prime}$ & Reduced surrounding air speed $u^{\prime}=u-3$ m/s & $\mathrm{m} / \mathrm{s}$ \\
$\eta_{0, b}$ & Peak collector efficiency based on beam irradiance $G_{b}$ & -- \\
$\eta_{0, h e m}$ & Peak collector efficiency based on hemispherical irradiance $G_{h e m}$ & -- \\
$\vartheta_{a}$ & Measured ambient air temperature & $\circ \mathrm{o}$ \\
$\vartheta_{m}$ & Mean temperature of heat transfer fluid & $\circ \mathrm{o}$ \\
$\sigma$ & Stefan-Boltzmann constant & $\mathrm{W} /\left(\mathrm{m}^{2} \mathrm{~K}^{4}\right)$ \\
$\varepsilon$ & Hemispherical emittance & $\%$ \\
$\alpha$ & Solar absorptance & $\%$ \\
\hline
\end{tabular}

\subsection{Reduced Quasi-Dynamic Test model using G*}

(Based on contribution by N. Amrizal; for further reading, see [N. Amrizal et al. 2013]) The model is based on ISO quasi dynamic method with replacement of solar radiation term by useful thermal radiation. The useful thermal radiation, $G^{*}$, is defined as the effective solar radiation which the collector converts into thermal power. So, the radiation fraction transformed into electrical power $\left(P_{e l}\right)$ by the $\mathrm{PV}$ cells is subtracted to the total solar radiation. Thus, $G^{*}=G-P_{e l}$

The thermal power output is thus given by:

$P_{t h}=A_{G}\left[F^{\prime}(\tau \alpha)_{e n} k_{\theta} G^{*}-a_{1}\left(\vartheta_{m}-\vartheta_{a}\right)-a_{2}\left(\vartheta_{m}-\vartheta_{a}\right)^{2}-a_{5}\left(d \vartheta_{m} / d t\right)\right]$

Where,

$F^{\prime} \quad$ Collector efficiency factor

$F^{\prime}(\tau \alpha)_{e n} \quad$ Zero loss efficiency

\subsubsection{1D Energy balance model}


(Based on contribution by L. Brottier)

The module is assimilated to a succession of layers: glass, encapsulant, cells, backsheet, exchanger, fluid and insulant (Figure 4).

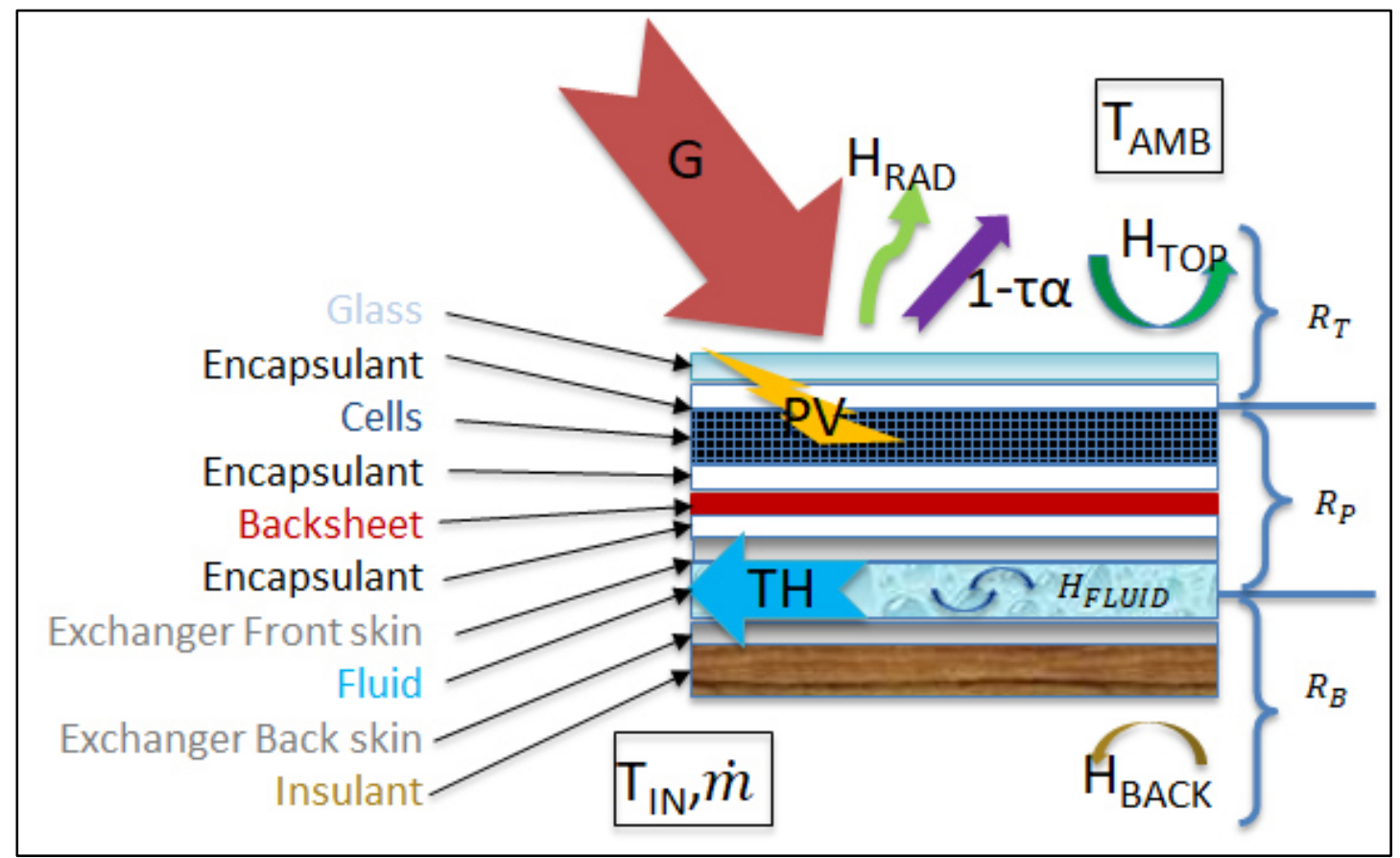

Figure 4: Sketch of the resistance model to describe the physics of a PVT collector made of the different material layers

1st equation on the PV cells ( $x=$ direction of fluid):

$\underbrace{(\tau \alpha) \cdot G \cdot\left(1-\eta_{\mathrm{PV}}\left(\mathrm{G}, \mathrm{T}_{\mathrm{PV}}\right)\right)}_{\text {Transmitted solar energy }}$

$=\underbrace{\operatorname{Hrad}\left(\mathrm{T}_{\mathrm{PV}}-\mathrm{T}_{\mathrm{s} y}\right)}_{\text {Radiative exchange with the sky }}+\underbrace{\frac{\mathrm{T}_{\mathrm{PV}}-\mathrm{T}_{\mathrm{amb}}}{R_{T}}}_{\text {Front side convective exchange }}+\underbrace{\frac{\mathrm{T}_{\mathrm{PV}}-\mathrm{T}_{\mathrm{fluid}}}{R_{P}}}_{\text {convective exchange with the fluid }}$

$\Rightarrow \mathrm{T}_{\mathrm{PV}}(x)=\mathrm{A} \cdot \mathrm{T}_{\mathrm{FLUID}}(x)+\mathrm{B}$

2nd equation on a fluid slice:

$\underbrace{\frac{T_{P V}-T_{F L U I D}}{R_{P}}}_{\text {Convective exchange with the fluid }}=\underbrace{\frac{T_{F L U I D}-T_{B A C K}}{R_{B}}}_{\text {Back side convective exchange }}+\frac{\dot{m} \cdot \mathrm{Cp}}{\text { Lenght }} \cdot \frac{\mathrm{d} T_{F L U I D}}{\mathrm{dx}}$

$\Rightarrow \frac{d T_{F L U I D}}{d x}+D \cdot T_{F L U I D}(x)-C . D=0$

$\Rightarrow \mathrm{T}_{\mathrm{FLUID}}(x)=\left(\mathrm{T}_{\mathrm{F}, \text { IN }}-\mathrm{C}\right) \cdot \mathrm{e}^{-\mathrm{D} \cdot x}+\mathrm{C}$ 
The result is solved by iteration (first $T_{P V}$ is assumed, then (re)calculated)

$\mathrm{T}_{\mathrm{F}, \mathrm{OUT}}=\left(\mathrm{T}_{\mathrm{F}, \mathrm{IN}}-\mathrm{C}\right) \cdot \mathrm{e}^{- \text {D.Width }}+\mathrm{C}$

$\mathrm{T}_{\mathrm{F}, \mathrm{MEAN}}=\frac{\left(\mathrm{T}_{\mathrm{F}, \mathrm{IN}}-\mathrm{C}\right)}{\mathrm{D} \cdot \text { Width }} \cdot\left(1-\mathrm{e}^{- \text {D.Width }}\right)+\mathrm{C}$

$\mathrm{T}_{\mathrm{PV}}=\mathrm{A} \cdot \mathrm{T}_{\mathrm{F}, \mathrm{MEAN}}+\mathrm{B}$

Where,

$\tau \alpha \quad$ Transmittance / absorptance coefficient

$\begin{array}{ll}\text { G Global suface irradiation } & W / \mathrm{m}^{2}\end{array}$

$\mathrm{T}_{\mathrm{PV}} \quad$ Temperature of the cells

$\eta_{\mathrm{PV}}\left(\mathrm{G}, \mathrm{T}_{\mathrm{PV}}\right)$ Cell photovoltaic efficiency at a given irradiation $(\mathrm{G})$ and temperature of the cells $\left(\mathrm{T}_{\mathrm{PV}}\right)$

$\mathrm{T}_{\text {sky }} \quad$ Temperature of the sky

$\mathrm{T}_{\mathrm{amb}} \quad$ Temperature of the front ambient air (wind)

$\mathrm{T}_{\text {back }} \quad$ Temperature of the back ambient air

$\mathrm{T}_{\text {fluid }} \quad$ Temperature of the fluid

$\dot{\mathrm{m}} \quad$ Fluid mass flowrate

$\mathrm{Cp} \quad$ Fluid thermal capacity

$\mathrm{H}_{\mathrm{rad}} \quad$ Radiative exchange coefficient with the sky

$\mathrm{R} \quad$ Equivalent thermal resistance

$\mathrm{kg} / \mathrm{h}$

$\mathrm{Wh} / \mathrm{kg} / \mathrm{K}$

$\mathrm{Wh} / \mathrm{m}^{2} / \mathrm{K}$

$\mathrm{m}^{2} \mathrm{~K} / \mathrm{W}$

$\boldsymbol{R}_{\boldsymbol{P}}=\frac{e_{\text {cell }}}{k_{\text {cell }}}+\frac{e_{\text {encapsulant }}}{k_{\text {encapsulant }}}+\frac{e_{\text {BackSheet }}}{k_{\text {BackSheet }}}+\frac{e_{\text {encapsulant }}}{k_{\text {encapsulant }}}+\frac{e_{\text {echFrontSkin }}}{k_{\text {echFrontSkin }}}+\frac{1}{H_{F L U I D}}$,

$\boldsymbol{R}_{\boldsymbol{T}}=\frac{e_{\text {glass }}}{k_{\text {glass }}}+\frac{e_{\text {encapsulant }}}{k_{\text {encapsulant }}}+\frac{1}{H_{T O P}}$

$\boldsymbol{R}_{\boldsymbol{B}}=\frac{e_{\text {echBackSkin }}}{k_{\text {echBackSkin }}}+\frac{e_{\text {insulant }}}{k_{\text {insulant }}}+\frac{1}{H_{F L U I D}}+\frac{1}{H_{B A C K}}$

\section{With}

e Thickness m

$\begin{array}{ll}\text { k Conductivity } & \mathrm{Wh} / \mathrm{m} / \mathrm{K}\end{array}$

$\mathrm{H}_{\text {top }} \quad$ Convective exchange coefficient with the front wind $\quad \mathrm{Wh} / \mathrm{m}^{2} / \mathrm{K}$

$\mathrm{H}_{\text {fluid }} \quad$ Convective exchange coefficient with the fluid $\mathrm{Wh} / \mathrm{m}^{2} / \mathrm{K}$

$\mathrm{H}_{\text {back }} \quad$ Convective exchange coefficient with $\mathrm{T}_{\mathrm{amb}}$ 
An issue is to determine accurate models for the convective exchange coefficients.

It has been used:

$\mathrm{T}_{\text {sky }}=\mathrm{T}_{\mathrm{amb}}-6^{\circ} \mathrm{K}$

$\mathrm{H}_{\mathrm{RAD}}=\varepsilon \cdot \sigma \cdot\left(\mathrm{T}_{\mathrm{PV}}^{2}+\mathrm{T}_{\mathrm{SKY}}^{2}\right) \cdot\left(\mathrm{T}_{\mathrm{PV}}+\mathrm{T}_{\mathrm{SKY}}\right)$

With

$\varepsilon: \quad \quad$ Glass emissivity taken at $\varepsilon \sim 0.9$, and

$\sigma: \quad$ Stefan constant at $\sigma \sim 5,67.10^{-8} \mathrm{~W} / \mathrm{m}^{2} / \mathrm{K}^{-4}$

$\mathrm{H}_{\text {FLUID }}=800 \mathrm{~W} / \mathrm{m}^{2} / \mathrm{K} \quad$ (specific to the geometry of this heat exchanger)

$H_{T O P}=3,6 * V_{W I N D}+3,0 \quad$ with $V_{\text {WIND }}$ as wind velocity $(\mathrm{m} / \mathrm{s})$, but also

$H_{T O P}=8,4 \mathrm{~W} / \mathrm{m}^{2} / \mathrm{K} \quad$ (wind fixed at $1,5 \mathrm{~m} / \mathrm{s}$ )

$\mathrm{H}_{\mathrm{BACK}}=5 \mathrm{~W} / \mathrm{m}^{2} / \mathrm{K} \quad$ when integrated instead of tiles (modules make the

waterproofness of the roof)

\subsubsection{Thermal output method based on MFC model Isakson/Eriksson Trnsys Type 301}

\section{(Based on contribution by M. Proell)}

Thermal power balance at collector (dynamic) is given by:

$C_{K} \frac{\partial \bar{T}}{\partial t}+m c_{p} \frac{\partial \bar{T}}{\partial t}=A_{\text {Koll }}\left[\eta_{0}^{U_{O C}} G_{\text {tot }}^{\text {Koll }}-q_{\text {ver }}^{\cdot}\right]-P_{p v}$

Influence of wind, optical losses, and longitudinal and transverse incidence angle modifier is considered in the model.

Parameters for calculating $Q_{u s e}=q(T)$

$q(T)=F^{\prime}(T)\left(S-U_{t}(T)\left(T-T_{e}\right)-\left(U_{b}+U_{w} v_{w}\right)\left(T-T_{a}\right)\right.$

Where,

$F^{\prime}(T) \quad$ Collector efficiency factor

$T_{e} \quad$ Effective environmental temperature $\quad{ }^{\circ} \mathrm{C}$

$U_{t}(T) \quad$ Collector top loss coefficient $\quad \mathrm{W} / \mathrm{Km}^{2}$

$\begin{array}{lll}U_{b} & \text { Collector back loss coefficient } \quad \mathrm{W} / \mathrm{Km}^{2}\end{array}$

$\begin{array}{lll}U_{w} & \text { Collector wind dependent loss coefficient } \quad \mathrm{J} / \mathrm{Km}^{3}\end{array}$ 


\subsubsection{Analytical model}

(Based on contribution by M. Herrando, N. Pokorny)

The model described below is based on Florscheutz approach applied for analysis of PVT collectors which in turn is an extension of Hottel-Whillier model [L. Florschuetz 1979].

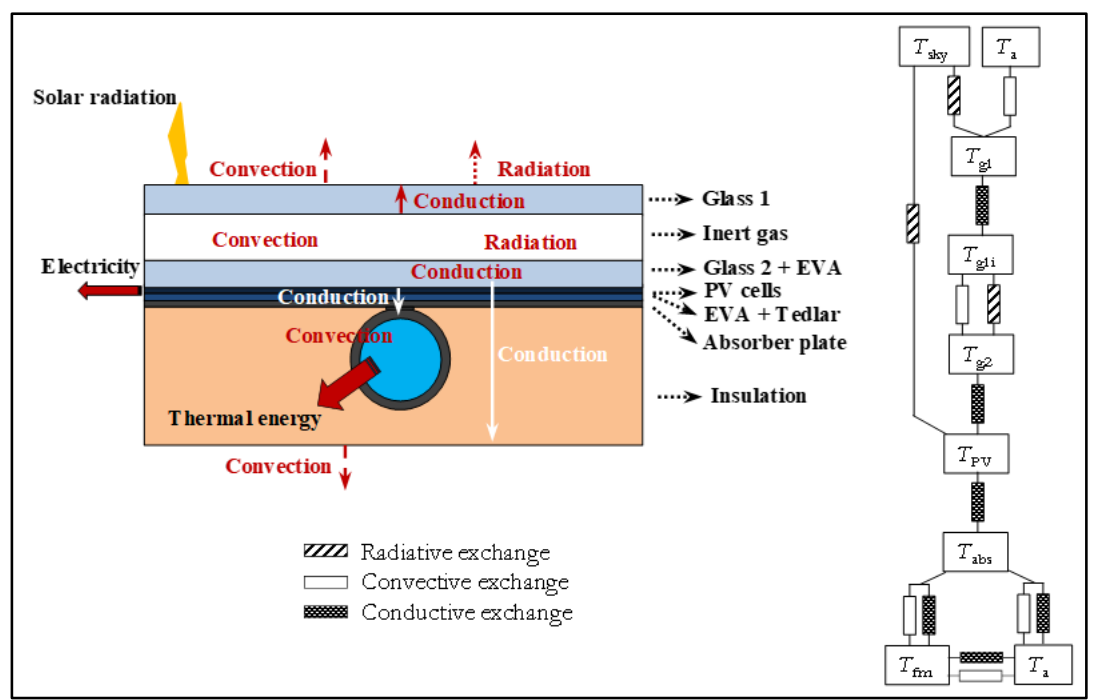

Figure 5: (left) PVT collector cross-section for the parallel tubes (sheet-and-tube, not to scale) and (right) diagram of thermal resistances through the various PVT collector layers (Herrando et al. 2014; Herrando et al. 2018).

This set of equations can also be found in the book Solar Engineering of Thermal Processes by Duffie \& Beckmann [J. Duffie and W. Beckman 1991].

In order to evaluate the heat flux throughout the collector and to obtain the temperature distribution, the energy balance equation is applied to each of the collector layers [M. Herrando et al. 2014; M. Herrando et al. 2018]. In this way, the average temperatures of all the separate collector layers are estimated. The main heat transfer mechanisms are radiation (from the glass and the PV module to the sky, and the surface to surface radiation between Glass 1 and Glass 2), convection (from the outer surfaces to the ambient, within Glass 1 and Glass 2, and from the tubes/channels to the heat transfer fluid) and conduction between all solid layers.

The proposed method is used for steady-state conditions [H. Zondag et al. 2003; A. Tiwari and M. Sodha 2006] and it is developed under the following main assumptions:

- solar radiation is absorbed only by the thermal collector [R. Agarwal and $\mathrm{H}$. Garg 1994] and the absorption in the cover glass and in the frame is neglected;

- the ambient temperature is considered uniform around the module [G. Notton et al. 2005;C. Cristofari et al. 2009]

- heat losses at the sides of the PVT collector are negligible [G. Notton et al. 2005]; 
- solar irradiance (set as constant) is uniform on the collector surface; the water mass flow-rate is distributed uniformly among all riser tubes [C. Cristofari et al. 2009; S. Bhattarai et al. 2012];

- radiative thermal exchanges between the sides of the solar collectors' channels are neglected [B. Sandnes and J. Rekstad 2002; H. Zondag et al. 2002; T. Chow 2003; C. Cristofari et al. 2009]

After neglecting the absorption of solar radiation by the top layer (glass cover) at short wavelengths, given the very low absorptivity of glass $\left(\alpha_{\mathrm{g}, \text { short }}=0.05\right)$, the global energy balance of the PVT collector is [M. Herrando et al. 2014; J. Antonanzas et al. 2015].

$$
S=w_{\mathrm{e}}+q_{\mathrm{top}}+q_{\mathrm{cd}, \mathrm{ca}}
$$

where $w_{\mathrm{e}}$ is the electrical yield of the system and $S$ is the absorbed solar irradiance, calculated as:

$$
S=(\tau \alpha)_{\mathrm{PV}} I_{\mathrm{t}}
$$

with $I_{\mathrm{t}}$ being the total solar irradiance per square meter $\left(\mathrm{W} / \mathrm{m}^{2}\right)$, and $(\tau \alpha)_{\mathrm{PV}}$ the transmittance-absorptance product for the PV module, which can be calculated as [J. Duffie and W. Beckman 1991],

$$
(\tau \alpha)_{\mathrm{PV}}=\frac{\tau_{\mathrm{g}, \mathrm{short} \lambda} \alpha_{\mathrm{PV}, \text { short } \lambda}}{1-\left(1-\alpha_{\mathrm{PV}, \text { short } \lambda}\right) \rho_{\mathrm{d}}}
$$

Here, $\tau_{\mathrm{g}, \text { short }}$ is the transmittance of the cover plate (glass), $\alpha_{\mathrm{PV} \text {,short }}$ is the absorptivity of the PV module, both at short wavelengths, and $\rho_{\mathrm{d}}$ is the diffuse reflectance of the cover plate. In the case of a single cover glass layer, a value of 0.16 is usually employed [J. Duffie and W. Beckman 1991; M. Herrando et al. 2014; M. Herrando et al. 2018].

The top losses from the glass cover are mainly due to convection caused by wind, radiation from the top glass to the atmosphere and radiation from the PV layer to the atmosphere due to glass transmittance at long wavelengths [S. Kalogirou 2009; M. Herrando et al. 2014; A. del Amo et al. 2016]

$$
\begin{aligned}
q_{\text {top }}=q_{\text {wind }} & +q_{\text {sky }}+q_{\text {rd,PVsky }} \\
& =h_{\text {cv,g1a }}\left(T_{\text {g1 }}-T_{\mathrm{a}}\right)+h_{\text {rd,g1sky }}\left(T_{\mathrm{g} 1}-T_{\text {sky }}\right) \\
& +h_{\text {rd,PVsky }}\left(T_{\text {cell }}-T_{\text {sky }}\right),
\end{aligned}
$$

where $q_{\text {top }}$ is the total heat loss to atmosphere, $q_{\text {wind }}$ is the forced convective heat loss to the ambient wind, $q_{\text {sky }}$ is the radiative heat flow from the glass cover to the atmosphere and $q_{\mathrm{rd}, P V s k y}$ is the radiative heat loss from the PV layer to the atmosphere at long wavelengths.

The heat flow through the glass cover and through the inert gas gap can be expressed as, 


$$
\begin{gathered}
q_{\mathrm{cd}, \mathrm{g} 1}=h_{\mathrm{cd}, \mathrm{g} 1}\left(T_{\mathrm{g} 1 \mathrm{i}}-T_{\mathrm{g} 1}\right), \\
q_{\mathrm{cd}, \mathrm{g} 1}=\left(h_{\mathrm{cv,g} 1 \mathrm{ig} 2}+h_{\mathrm{rd}, \mathrm{g} 1 \mathrm{ig} 2}\right)\left(T_{\mathrm{g} 2}-T_{\mathrm{g} 1 \mathrm{i}}\right) .
\end{gathered}
$$

Now, each heat flux term is considered separately. All heat fluxes here are in W per unit area $\left(\mathrm{W} / \mathrm{m}^{2}\right)$.

In order to model the convective heat exchange with the surroundings, the effect of the wind should be considered, and so a forced convective heat transfer coefficient is required [E. Skoplaki and J. Palyvos 2009]. Various expressions are given in different sources for the estimation of this coefficient [P. Lunde 1980; G. Notton et al. 2005; S. Bhattarai et al. 2012; J. Antonanzas et al. 2015; O. Rejeb et al. 2015], all of them dependent on the wind speed $\left(v_{\text {wind }}\right)$. These expressions do not differ significantly, and so it was decided to use the expression that provides intermediate values, within the range of the various predictions [M. Herrando et al. 2014]. Hence:

$$
h_{\mathrm{cv}, \mathrm{g} 1 \mathrm{ig} 2}=4.5+2.9 v_{\text {wind }} \text {. }
$$

The radiative heat loss to the atmosphere, $q_{\mathrm{sky}}$, can be calculated from [J. Duffie and W. Beckman 1991; F. Incropera et al. 2007],

$$
q_{\text {sky }}=\varepsilon_{\mathrm{g}, \text { long } \lambda} \sigma\left(T_{\mathrm{g} 1}^{4}-T_{\mathrm{sky}}^{4}\right)=h_{\mathrm{rd}, \mathrm{g} 1 \mathrm{sky}}\left(T_{\mathrm{g} 1}-T_{\mathrm{sky}}\right),
$$

where $\varepsilon_{g, \text { long } \lambda}$ is the emissivity of the glass cover at long wavelengths, $\sigma$ is the StefanBoltzmann constant $\left(\sigma=5.67 \cdot 10^{-8} \mathrm{~W} / \mathrm{m}^{2} \mathrm{~K}^{4}\right), T_{\mathrm{g} 1}$ is the temperature of the glass cover, and $T_{\text {sky }}$ is the sky temperature which can be found from the relation $T_{\text {sky }}=0.0552 T_{\mathrm{a}} \mathrm{T}^{1.5}$ [J. Duffie and W. Beckman 1991; G. Notton et al. 2005; C. Cristofari et al. 2009; M. Herrando et al. 2014], with $T_{a}$ in $\mathrm{K}$. Therefore, the radiative term, also referred to as 'radiation heat transfer coefficient' can be expressed as [J. Antonanzas et al. 2015; O. Rejeb et al. 2015],

$$
h_{\mathrm{rd}, \mathrm{g} 1 \mathrm{sky}}=\varepsilon_{\mathrm{g}, \mathrm{long} \lambda} \sigma\left(T_{\mathrm{g} 1}^{2}+T_{\mathrm{sky}}^{2}\right)\left(T_{\mathrm{g} 1}+T_{\mathrm{sky}}\right) .
$$

The radiative heat loss from the PV layer to the atmosphere, $q_{\mathrm{rd}, \mathrm{PV} \text { sky, }}$ accounts for the radiative heat flow emitted by the PV layer at long wavelengths that is not absorbed by the cover glass and therefore is lost to the atmosphere [J. Duffie and W. Beckman 1991]. This term can be estimated considering the emissivity of the PV layer and the transmittance of the cover glass at long wavelengths as follows,

$$
q_{\text {rd,PVsky }}=\tau_{\text {g,long } \lambda} \varepsilon_{\mathrm{PV}, \text { long } \lambda} \sigma\left(T_{\text {cell }}^{4}-T_{\text {sky }}^{4}\right)=h_{\text {rd,PVsky }}\left(T_{\text {cell }}-T_{\text {sky }}\right),
$$

where $\tau_{g, \text { long }}$ is the transmittance of the cover glass and $\varepsilon_{\mathrm{PV} \text {,long } \lambda}$ is the emissivity of the PV layer both at long wavelengths, and $T_{\text {cell }}$ is the temperature of the PV layer. Thus, the radiative coefficient can be expressed as,

$$
h_{\text {rd,PVsky }}=\tau_{\text {g,long } \lambda} \varepsilon_{\mathrm{PV}, \text { long } \lambda} \sigma\left(T_{\text {cell }}^{2}+T_{\text {sky }}^{2}\right)\left(T_{\text {cell }}+T_{\text {sky }}\right) \text {. }
$$


Conduction through the top glass depends on the glass thickness $\left(\delta_{\mathrm{g} 1}\right)$ and its thermal conductivity $\left(k_{\mathrm{g} 1}\right)$,

$$
h_{\mathrm{cd}, \mathrm{g} 1}=\frac{k_{\mathrm{g} 1}}{\delta_{\mathrm{g} 1}} .
$$

As shown in Eq. (12), the heat flux through the inert gas gap is due to both convection and radiation. According to [J. Duffie and W. Beckman 1991], the radiative heat transfer between two diffuse and infinity grey parallel plates of equal area at known temperatures, which is assumed here to be the case between the glass cover and the $\mathrm{PV}$ glass cover (with emissivity at long wavelengths $\varepsilon_{\mathrm{PV}, \text { long }}$ ), can be obtained from,

$$
q_{\mathrm{rd}, \mathrm{g} 1 \mathrm{ig} 2}=\sigma \frac{T_{\mathrm{g} 2}^{4}-T_{\mathrm{g} 1 \mathrm{i}}^{4}}{1 / \varepsilon_{\mathrm{PV}, \text { long } \lambda}+1 / \varepsilon_{\mathrm{g}, \text { long } \lambda}-1}
$$

and thus, the radiation heat transfer coefficient between these layers can be expressed as [T. Chow et al. 2005; J. Antonanzas et al. 2015; O. Rejeb et al. 2015],

$$
h_{\mathrm{rd}, \mathrm{g} 1 \mathrm{ig} 2}=\frac{\sigma\left(T_{\mathrm{g} 2}^{2}-T_{\mathrm{g} 1 \mathrm{i}}^{2}\right)\left(T_{\mathrm{g} 2}+T_{\mathrm{g} 1 \mathrm{i}}\right)}{1 / \varepsilon_{\mathrm{PV}, \text { long } \lambda}+1 / \varepsilon_{\mathrm{g}, \text { long } \lambda}-1} .
$$

Finally, the convective heat transfer coefficient between the glass cover and the PV glass cover can be estimated based on the estimation of a suitable Nusselt number $(\mathrm{Nu})$,

$$
h_{\mathrm{cv}, \mathrm{g} 1 \mathrm{ig} 2}=\frac{N u \cdot k}{\delta_{\mathrm{g} 1 \mathrm{ig} 2}}
$$

where $N u, k$ and $\delta_{\mathrm{g} 1 \mathrm{ig} 2}$ represent the Nusselt number, the thermal conductivity of the gas encapsulated in the gap, and the distance between the glass cover and the PV glass cover. To estimate Nu, several authors [T. Chow et al. 2005; S. Kalogirou 2009; J. Antonanzas et al. 2015; P. Haurant et al. 2015; O. Rejeb et al. 2015] have used an experimental equation proposed by [K. Hollands et al. 1976], as a function of the Rayleigh number $(R a)$ and tilt angle $(\beta)$, valid for tilt angles from $0^{\circ}$ to $60^{\circ}$,

$$
N u=1+1.44\left[1-\frac{1708}{R a \cos \beta}\right]^{+} \cdot\left[1-\frac{1708 \cdot(\sin 1.8 \beta)^{1.6}}{R a \cos \beta}\right]+\left[\left(\frac{R a \cos \beta}{5830}\right)^{0.3}-1\right]^{+} .
$$

In this equation, Eq. (22),the notation [... $]^{+}$is used to indicate terms that are only considered if their value is positive. Rayleigh number $(R a)$ is given by,

$$
R a=\frac{g \operatorname{Pr} \beta\left(T_{\mathrm{g} 2}-T_{\mathrm{g} 1 \mathrm{i}}\right) \delta_{\mathrm{g} 1 \mathrm{ig} 2}^{3}}{v^{2}} .
$$


For titled surfaces, $R a<1,700$ means that the only heat transfer mechanism among the gas particles is conduction, whereas for $R a>1,700$ natural convection starts to appear.

Since a linear heat transmission is considered, heat fluxes across layers (glass cover, inert gas gap, and PV glass cover) are equal. Therefore, Eqs. (10) and (11) are equal to

$$
q_{\mathrm{cd}, \mathrm{g} 2}=h_{\mathrm{cd}, \mathrm{g} 2}\left(T_{\text {cell }}-T_{\mathrm{g} 2}\right),
$$

where $h_{\mathrm{cd}, \mathrm{g} 2}$ is the equivalent heat transfer coefficient for conduction through the PV glass cover,

$$
h_{\mathrm{cd}, \mathrm{g} 2}=\frac{1}{\frac{\delta_{\mathrm{g} 2}}{k_{\mathrm{g} 2}}+\frac{\delta_{\mathrm{eva}}}{k_{\mathrm{eva}}}} .
$$

Finally, the heat flow between the PV cells and the absorber $\left(q_{\mathrm{cd}, \mathrm{ca}}\right)$ in Eq.(7) can be estimated as [H. Zondag et al. 2003; M. Herrando et al. 2014],

$$
q_{\mathrm{cd}, \mathrm{ca}}=U_{\mathrm{bond}}\left(T_{\text {cell }}-T_{\mathrm{abs}}\right),
$$

where $T_{\text {abs }}$ is the temperature of the absorber plate, and $U_{\text {bond }}$ is the heat transfer coefficient of the bonding, from the PV cell to the absorber plate, which is composed by the following layers: a pc-Si wafer, which has a very high thermal conductivity compared with the other layers (with $k \approx 149 \mathrm{~W} / \mathrm{m} \mathrm{K}$ ) and is therefore neglected, a 0.5 $\mathrm{mm}$ EVA layer $(k=0.35 \mathrm{~W} / \mathrm{m} \mathrm{K})$ and a $0.3 \mathrm{~mm}$ thick Tedlar layer $(k=0.36 \mathrm{~W} / \mathrm{m} \mathrm{K})$ [M. Herrando et al. 2014; J. Antonanzas et al. 2015],

$$
U_{\text {bond }}=\frac{1}{\frac{\delta_{\text {eva }}}{k_{\text {eva }}}+\frac{\delta_{\text {tedlar }}}{k_{\text {tedlar }}}} .
$$

The heat flow $q_{c d, c a}$ can be either transferred from the absorber layer to the cooling fluid $\left(q_{\mathrm{u}}\right)$, or lost through the underside insulation layer to the environment $\left(q_{\text {back }}\right)[\mathrm{H}$. Zondag et al. 2003; M. Herrando et al. 2014],

$$
q_{\mathrm{cd}, \mathrm{ca}}=q_{\mathrm{u}}+q_{\mathrm{back}}
$$

Here,

$$
q_{\text {back }}=U_{\text {back }}\left(T_{\mathrm{abs}}-T_{\mathrm{a}}\right)
$$

where $T_{\mathrm{a}}$ is the ambient temperature, and $U_{\text {back }}$ is the heat transfer coefficient between the absorber and the environment (through the back-layer insulation), which can be calculated from, 


$$
U_{\mathrm{back}}=\frac{1}{\frac{\delta_{\text {ins }}}{k_{\text {ins }}}+\frac{1}{h_{\mathrm{cv}, \mathrm{b}}}},
$$

where $\delta_{\text {ins }}$ and $k_{\text {ins }}$ are the thickness and thermal conductivity of the insulation layer respectively, and $h_{\mathrm{cv}, \mathrm{b}}$ is the convective heat transfer coefficient of air at the back of the PVT collector, which usually takes values between 0.3-0.6 W/m² $\mathrm{K}$ [S. Kalogirou 2009].

The heat transfer from the absorber to the water, also called useful heat, $q_{\mathrm{u}}$, is equal to the absorbed solar radiation minus the total heat losses from the surface to the surroundings by conduction, convection and radiation, which are represented by the product of the overall heat-loss coefficient, $U_{\mathrm{L}}$, times the difference between the absorber plate temperature, $T_{\text {abs}}$, and the ambient temperature, $T_{\mathrm{a}}$, as follows [S. Kalogirou 2009],

$$
q_{\mathrm{u}}=S-U_{\mathrm{L}}\left(T_{\mathrm{abs}}-T_{\mathrm{a}}\right)
$$

This term can also be estimated by [X. Zhang et al. 2012; M. Herrando et al. 2014],

$$
q_{\mathrm{u}}=\frac{\dot{m}_{\mathrm{c}} c_{\mathrm{p}}\left(T_{\mathrm{out}}-T_{\mathrm{in}}\right)}{A_{\mathrm{c}}}
$$

with $\dot{m}_{\mathrm{c}}$ the mass flow-rate of water through the collector, $c_{p}$ the specific heat capacity of water and $A_{c}$ the PVT collector aperture area.

In Eq.(31), the overall heat-loss coefficient, $U_{\mathrm{L}}$, can be estimated by,

$$
\begin{gathered}
U_{\mathrm{L}}=U_{\text {top }}+U_{\text {back }}, \\
U_{\text {top }}=\frac{1}{\frac{1}{h_{\mathrm{cv}, \mathrm{g} 1 \mathrm{a}}+h_{\mathrm{rd}, \mathrm{g} 1 \mathrm{sky}}}+\frac{1}{h_{\mathrm{cd}, \mathrm{g} 1}}+\frac{1}{h_{\mathrm{cv}, \mathrm{g} 1 \mathrm{ig} 2}+h_{\mathrm{rd}, \mathrm{g} 1 \mathrm{~g} 2}+h_{\mathrm{rd}, \mathrm{PV} s \mathrm{y}}}+\frac{1}{h_{\mathrm{cd}, \mathrm{g} 2}}} .
\end{gathered}
$$

To express the useful heat in terms of the fluid inlet temperature, $T_{\text {in }}$, the heat removal factor, $F_{\mathrm{R}}$, should be used, which represents the ratio of the actual useful energy gain that would result if the collector-absorbing surface had been at the local fluid temperature [S. Kalogirou 2009],

Thus, the thermal power output is given by:

$$
P_{t h}=A_{\mathrm{c}} F_{\mathrm{R}}\left(S-U_{\mathrm{L}}\left(T_{\mathrm{in}}-T_{\mathrm{a}}\right)\right),
$$

where,

$$
F_{\mathrm{R}}=\frac{\dot{m}_{\mathrm{c}} C_{\mathrm{p}}}{A_{\mathrm{c}} U_{\mathrm{L}}}\left[1-e^{\frac{-F^{\prime} A_{\mathrm{c}} U_{\mathrm{L}}}{\dot{m}_{\mathrm{c}} c_{\mathrm{p}}}}\right],
$$




$$
\begin{gathered}
F^{\prime}=\frac{\frac{1}{U_{\mathrm{L}}}}{W\left[\frac{1}{U_{\mathrm{L}(D+(W-D) F)}}+\frac{1}{C_{\mathrm{bond}}}+\frac{1}{\pi D_{\mathrm{i}} h_{\mathrm{fi}}}\right]}, \\
F=\frac{\tanh \left[m \frac{W-D}{2}\right]}{\left[m \frac{W-D}{2}\right]}, \\
m=\sqrt{\frac{U_{\mathrm{L}}}{k_{\mathrm{abs}} \delta_{\mathrm{abs}}+k_{\mathrm{PV}} \delta_{\mathrm{PV}}+k_{\mathrm{eva}} \delta_{\mathrm{eva}}}} .
\end{gathered}
$$

Similar mathematical model is implemented into the TRNSYS that calculates energy flow from PVT absorber surface to ambient and energy flow from PVT absorber surface to liquid, all in every time step. A detailed calculation of the heat transfer from the collector absorber to ambient (heat loss) and from the collector absorber to the heat transfer liquid (internal balance) is performed within the iterative loops. The model inputs are the detailed geometrical, thermal, electrical and optical properties (about 40 parameters) of individual segments of the PVT collector together with operation and climatic conditions. Temperature distribution in the solar collector is calculated in the iteration loops. The original steady-state model has been extended to a dynamic model by the introduction of the effective thermal capacity term available from testing or calculation [N. Pokorny et al. 2016].

The TRNSYS model considers $S\left[\mathrm{~W} / \mathrm{m}^{2}\right]$ as,

$$
S=G \tau \alpha\left(1-\frac{\eta_{a} \cdot P F}{\alpha}\right)
$$

Where, $\alpha$ solar absorptance of the PVT absorber [-], $T$ is transmittance of the glass cover [-] and $\eta_{a}$ is photoelectric efficiency as a function of ambient temperature $T_{\mathrm{a}}$ calculated as

$$
\eta_{\mathrm{a}}=\eta_{\mathrm{ref}}\left[1-\beta \cdot\left(T_{\mathrm{a}}-T_{\mathrm{STC}}\right)\right] \cdot\left[1-k \cdot \ln \cdot\left(\frac{G}{G_{\mathrm{STC}}}\right)\right]
$$

$U_{L}$ is given by

$$
U_{\mathrm{L}}=U-P F \eta_{r e f} \tau_{g} G \beta_{r e f}
$$

Where $\mathrm{U}\left[\mathrm{W} / \mathrm{m}^{2} \mathrm{~K}\right]$ is the PVT collector heat loss coefficient from absorber to ambient related to aperture area, $\tau_{g}[-]$ is the transmittance of the glass cover and $P F[-]$ is the packing factor (related to aperture area).

And $P_{\text {th }}$ is given as below: 


$$
P_{t h}=A_{\mathrm{c}} F_{\mathrm{R}}\left(S-U_{\mathrm{L}}\left(T_{\mathrm{in}}-T_{\mathrm{a}}\right)\right)-C A_{\mathrm{c}} \frac{d t_{m}}{d \tau}
$$

Where, $C\left[\mathrm{~J} / \mathrm{m}^{2} \mathrm{~K}\right]$ is the effective thermal capacity of PVT collector, $\mathrm{t}_{\mathrm{m}}\left[{ }^{\circ} \mathrm{C}\right]$ is mean fluid temperature, and $d \tau$ is time step of simulation.

\subsubsection{Model determining an exergy factor}

\section{(Based on contribution by A. Gagliano and G. Tina)}

The model based on the Second Law of Thermodynamics allows a proper evaluation of the quality of each energy flux, through the concept of exergy or available energy. The exergy quantifies the maximum useful work that can be obtained during a process that brings the system to a complete equilibrium with the environment. Exergy analysis is a highly effective method of analysis for thermal processes because it provides insight that cannot be obtained by a mere energy analysis.

The thermal energy has an exergy content that depends by the temperature at which the thermal output is available. This issue is particularly relevant in PVT systems, where the energy yield is highly influenced by the enthalpy content of the operative fluid.

The exergy content of a mass flow in relation to its temperature can be defined as:

$$
\dot{E x_{\dot{Q}}}=\dot{m}_{w} C_{p w}\left(T_{o u t}-T_{\text {in }}\right)\left(1-\left(T_{e} / T_{\text {out }}\right)\right.
$$

Where,

$\begin{array}{lll}\dot{m}_{w} & \text { Mass flow rate } & \mathrm{kg} / \mathrm{s} \\ C_{p w} & \text { Specific heat of water } & \mathrm{J} / \mathrm{kgK} \\ \mathrm{T}_{\text {out }} & \text { Fluid temperature at the outlet of the solar collector } & \mathrm{K} \\ \mathrm{T}_{\mathrm{in}} & \text { Fluid temperature at the inlet of the solar collector } & \mathrm{K} \\ \mathrm{T}_{\mathrm{e}} & \text { Minimum outdoor temperature } & \mathrm{K}\end{array}$

For calculating the exergy efficiency, the exergy content of the solar radiation incident on the collector surface, which is the input to a solar energy system, has to be assessed.

[R. Petela 1961] proposes the most consolidated formulation for the exergy of the solar beam irradiance:

$$
\dot{E} x_{\text {sol }}=I_{\text {sol }}\left[1-\frac{4}{3}\left(\frac{T_{e}}{T_{\text {sun }}}\right)+\frac{1}{3}\left(\frac{T_{e}}{T_{\text {sun }}}\right)^{4}\right]
$$

where $T_{\text {sun }}$ and $T_{e}$ are the temperatures of the radiation reservoir and the environment, respectively with $T_{\text {sun }}=5760 \mathrm{~K}$ 
The reference temperature $T_{e}$ corresponds to the minimum outdoor temperature registered during any given month on the basis of what suggested by [M. Pons 2012].

Thus the average exergy efficiency of heat recovery $\left(\xi_{t}\right)$ is defined as:

$$
\xi_{t}=\dot{E} x_{\dot{Q}} /\left(\dot{E} x_{s o l} A_{a b s}\right)
$$

It can be observed that a shortcoming of PVT technology is that the electricity production increases at low temperatures, whereas the thermal energy usability is greater at high temperatures. Thus the definition of the operational conditions has extreme importance for maximizing the total exergy harvested by a PVT system.

The exergy method does not allow a proper comparison of the "value" of these two different forms of energy if the heat is not to be used to produce work. The use of this method is strongly discouraged within the IEA SHC Task 35 [M. Collins and $\mathrm{H}$. Zondag 2009].

\subsubsection{Operating Below Ambient Temperature}

(Based on contribution by C. Schmidt, M. Lämmle, K. Kramer)

\subsubsection{Model including condensation and freezing}

The model is based on ISO 9806 QDT approach with additional considerations. The following changes were included:

1. In the long wave radiation term $T_{a}$ is replaced by $T_{m}$ in order to have the sky radiation as a correction term by equating the average temperature $T_{m}$ of the collector and not the ambient temperature $T_{a}$.

2. The term $+a_{10}(2.8+3.0 u)\left(\mu_{a}-\mu_{s a t}\left(\vartheta_{m}\right)\right)$ is added to compensate for evaporation/condensation effects [J. Duffie and W. Beckman 1991].

3. When the collector temperature is lower than the ambient, there is a power supplied by the collector. So, $\left(\vartheta_{m}-\vartheta_{a}\right)^{2}$ is replaced by $\left(\vartheta_{m}-\vartheta_{a}\right)\left|\vartheta_{m}-\vartheta_{a}\right|$.

4. For this particular model, the incidence angles are not taken into account due to the position of the collectors in relation to the surrounding buildings and thus optical efficiency terms $\eta_{0, b} K_{b}\left(\theta_{L}, \theta_{T}\right) G_{b}+\eta_{0, b} K_{d} G_{d}$ are simplified to $\eta_{0} G$.

5. The term $+a_{9}\left(\sigma T_{b}^{4}-\sigma T_{m}^{4}\right)$ is added to include effects of long wave radiation on the rear of the collector.

6. The term $+a_{11} m_{w a t} c_{p \text { wat }}\left(\vartheta_{w a t}-\vartheta_{m}\right)$ is added to include effects of rain. An experimental validation for this term has not been carried out.

Thus, the final equation considering the above changes is given by

$$
\begin{aligned}
P_{t h}=A_{G}\left[\eta_{0} G\right. & -a_{1}\left(\vartheta_{m}-\vartheta_{a}\right)-a_{2}\left(\vartheta_{m}-\vartheta_{a}\right)\left|\vartheta_{m}-\vartheta_{a}\right|+a_{3} u\left(\vartheta_{m}-\vartheta_{a}\right)+a_{4}\left(E_{L}\right. \\
& -a_{5}\left(d \vartheta_{m} / d t\right)-a_{6} u G+a_{9}\left(\sigma T_{b}^{4}-\sigma T_{m}^{4}\right)+a_{10}(2.8+3.0 u)\left(\mu_{a}\right. \\
& \left.\left.-\mu_{s a t}\left(\vartheta_{m}\right)\right)+a_{11} m_{\text {wat }} c_{p \text { wat }}\left(\vartheta_{\text {wat }}-\vartheta_{m}\right)\right]
\end{aligned}
$$


Where,

$\begin{array}{lll}T_{b} & \text { Building temperature } & \mathrm{kg} / \mathrm{s} \\ T_{m} & \text { Mean temperature of heat transfer fluid } & \mathrm{K} \\ a_{9} & \begin{array}{l}\text { Long wave radiation dependence of the heat losses/gains } \\ \text { coefficient - rear side }\end{array} & -- \\ a_{10} & \text { Condensation/evaporation dependence coefficient } & -- \\ a_{11} & \text { Rain dependence of thermal heat losses/gains coefficient } & \mathrm{J} / \mathrm{kg} \\ \mu_{a} & \text { Absolute humidity of the ambient air } & \mathrm{kg} / \mathrm{m}^{3} \\ \mu_{\text {sat }}\left(\vartheta_{m}\right) & \text { Saturated absolute humidity of the ambient air at temperature } \vartheta_{m} & \mathrm{~kg} / \mathrm{m}^{3} \\ m_{\text {wat }} & \text { Rain water flow rate } & \mathrm{kg} / \mathrm{s} \\ c_{p \text { wat }} & \text { Effective thermal capacitance of the rain water } & \mathrm{J} / \mathrm{kgK} \\ \vartheta_{\text {wat }} & \text { Rain water temperature } & \stackrel{\mathrm{o}}{ }\end{array}$

The model is based on Bunea [M. Bunea et al. 2015] equation with leaving terms for rain water flow rate and back side radiative losses.

$$
\begin{array}{r}
P_{\text {ther }}=k_{b} G_{b} \eta_{0, t h}+k_{d} G_{d} \eta_{0, t h}-a_{1}\left(T_{m}-T_{a}\right)-a_{2}\left(T_{m}-T_{a}\right)\left|T_{m}-T_{a}\right|-a_{3} u\left(T_{m}-T_{a}\right) \\
+a_{4}\left(E_{L}-\sigma T_{m}^{4}\right)-a_{5} d T_{m} / d t-a_{6} u G+a_{10}(2.8+3 u)\left(\mu_{a}-\mu_{\text {sat }}\left(T_{m}\right)\right)
\end{array}
$$

\subsubsection{Night cooling}

\section{(Based on contribution by N. Pokorny)}

Night radiative cooling has been deeply studied over the last 20 years [A. Argiriou et al. 1994; E. Erell and Y. Etzion 2000; A. Dimoudi and A. Androutsopoulos 2006; M. Farmahini et al. 2010; T. Pean et al. 2015]. High heat losses of unglazed PVT collectors can be used for the night cooling applications.

The utilization of unglazed PVT collectors for the night cooling has already been investigated by the University of Stuttgart within Solar Decathlon competition [U. Eicker and A. Dalibard 2011]. A model of unglazed PVT collector, which would take into account operational conditions during the night time and below ambient temperature, is still not available in TRNSYS library. At the same time there is Type $50 \mathrm{~b}$ for PVT collector which is convenient only for day time simulations.

Also well-known type 203 for unglazed PVT collector is not applicable for night time. Due to this fact a new type of unglazed PVT collector was developed and implemented into the TRNSYS (type 233). The model is based on the external and internal energy balance. Both balances proceed in the iteration loop. External energy balance calculates heat transfer between ambient and absorber. Internal energy balance calculates heat transfer between absorber and heat transfer fluid. The model does not consider freezing and condensation gains. The mathematical model 
considers different direction of radiative and convective heat flux when ambient air temperature is higher than collector fluid temperature.

Moreover, the model takes into account geometrical and physical properties of the absorber by fin efficiency factor $F^{\prime}[-]$. Using the heat removal factor $F_{R}[-]$ it is possible to calculate collector cooling power from inlet temperature. Heat removal factor is given by

$$
F_{R}=\frac{\dot{m} \cdot c}{A_{G} \cdot U}\left[1-\exp \left(-\frac{A_{G} \cdot U \cdot F^{\prime}}{\dot{m} \cdot c}\right)\right]
$$

where $\dot{m}[\mathrm{~kg} / \mathrm{s}]$ is mass flow rate, $A_{G}$ is gross area of the collector and $U\left[\mathrm{~W} / \mathrm{m}^{2} . \mathrm{K}\right]$ is overall heat transfer coefficient. Cooling power during the night time is determined from heat flux balance.

To consider different absorber properties and geometry, the well-known Duffie and Beckman equation [J. Duffie and W. Beckman 1991] was modified. This model to determine night cooling power the solar heat gain was replaced by radiative heat loss and as a result the cooling performance is given by:

$$
\dot{Q}_{c}=F_{R} \cdot A_{G}\left[-\sigma \cdot \varepsilon_{a b s} \cdot\left(T_{a b s}^{4}-T_{s k y}^{4}\right)-U \cdot\left(T_{i n}-T_{a}\right)\right]
$$

where $T_{\text {in }}[\mathrm{K}]$ is fluid inlet temperature to the collector, $T_{a}[\mathrm{~K}]$ is ambient temperature, $\sigma\left[\mathrm{W} / \mathrm{m}^{2} . \mathrm{K}^{4}\right]$ is Stefan-Boltzmann constant, $\varepsilon_{a b s}[-]$ is emissivity of the PVT absorber surface, $T_{a b s}[\mathrm{~K}]$ is surface temperature of the absorber, and $T_{\text {sky }}[\mathrm{K}]$ is sky temperature.

\subsection{Electrical power output}

\subsubsection{Determination of cell temperature}

A very important step when calculating the PV efficiency, or the electrical yields, is to determine the PV cell temperature. The importance lies in the fact that an increasing cell temperature causes a decrease on the cell efficiency. Although this is not the only factor that may affect the electrical performance, it is probably the most studied one. Different methodologies can be used to calculate or estimate the cell temperature; some of them are presented in the following sub-chapters. In Chapter 2.2 onwards different methods to use the cell temperature to calculate the electrical energy yield are described.

\subsubsection{Assuming $\mathrm{T}_{\text {cell }} \approx \mathrm{T}_{\text {Fluid, out }}$}

(Based on contribution by L. Brottier)

One of the suggested methodologies is to simply consider the temperature on the PV cell TPV as an approximation of the fluid temperature at the collector outlet $T_{\text {Fluid,out . }}$ This approximation can be verified by performing an energy balance using a 1D model. 


$$
\frac{T_{\text {cell }}-T_{m}}{R_{\text {cell-fl }}}=\frac{P_{t h}+Q_{\text {back }}}{A}
$$

Where

$$
\frac{P_{t h}}{A}=\frac{\dot{m} \cdot C_{p} \cdot \Delta T}{A}
$$

Considering

$$
\frac{1}{R_{\text {cell-fl }}} \approx \frac{\dot{m} \cdot C_{p} \cdot 2}{A}
$$

This ultimately leads to

$$
T_{\text {fl-out }} \approx T_{\text {cell }}
$$

Some Software programs also assume to calculate the electrical instantaneous efficiency in every time step by the PV Formula:

$$
\eta_{\mathrm{PV}}=\eta_{\mathrm{ref}}\left[1-\beta \cdot\left(T_{\mathrm{cell}}-T_{\mathrm{STC}}\right)\right]
$$

Assuming the temperature for the cell is equal to the mean fluid temperature in this time step.

Software for calculation of PV yields, such as Polysun or PVGIS, use logarithmic functions to perform their calculations. This is, in a way, a similar approach to the one used by [C. Schmidt and A. Schäfer 2018].

\subsubsection{Analytical model}

\section{(Based on contribution by M. Herrando)}

Under this approach, an energy balance is performed at each of the collector layers. With this method, the average temperature of the layers can be estimated. A thermal resistance is considered between each of the layers and other additional considerations, such as an operation under steady-state conditions and negligible heat losses to the side.

Additional information on the energy balances can be found in Section 0

$$
T_{\text {cell }}=\frac{q_{c d . c a}}{U_{\text {bond }}}+T_{a b s}
$$

Where $q_{c d, c a}$ corresponds to the heat flow between PV cells and the absorber, $U_{\text {bond }}$ is the heat transfer coefficient of the bonding between PV cell and the absorber plate and Tabs is the temperature of the absorber. This is a very similar approach to the one used in Section 2.2.1.3, with an increase on the level of detail due to the consideration of multiple layer temperatures. 


\subsubsection{Analytical model with reduced complexity}

(Based on contribution by M. Lämmle, D. Jonas, J.-B. Beyssac; for a more detailed description and validation of the model, see [D. Jonas et al. 2019])

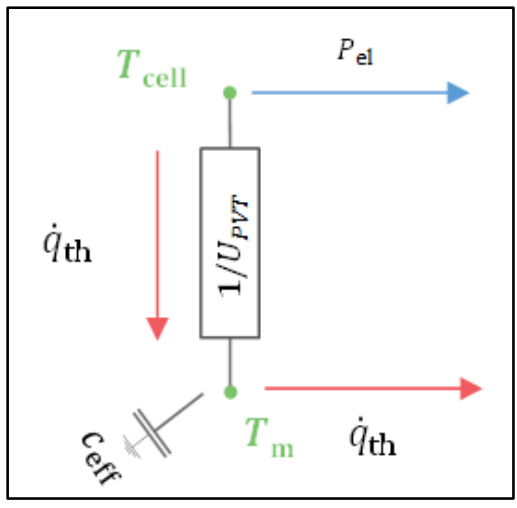

\section{Figure 6: Coupled PVT Model}

The main idea behind this model, which is based on the work of [M. Lämmle et al. 2017] and [D. Jonas et al. 2018b], is the development of a PVT performance model, which connects the quasi-dynamic thermal collector model of ISO 9806 with a PV performance model via a two-node model, which couples the cell node with the fluid node via the an internal heat transfer coefficient $U_{P V T}$ (see Figure 6).

The PVT cell temperature $T_{\text {cell }}$ is calculated via an equivalent thermal network with an internal heat transfer coefficient U $U_{P V T}$, which connects the PVT cell temperature with the mean fluid temperature $\mathrm{T}_{\mathrm{m}}$ of the PVT collector (see 12). The mean fluid temperature is calculated as mean temperature between the thermal model input and output temperature. The PVT cell temperature is then given by:

$$
T_{\text {cell }}=T_{\mathrm{m}}+\dot{q}_{\mathrm{th}} / U_{\mathrm{PVT}}
$$

where $\dot{q}_{\text {th }}$ is the specific thermal power output of the PVT collector. Therein, the constant coupling parameter $U_{P V T}$ is characterized by a parameter identification during steady-state or quasi-dynamic performance measurements according to ISO 9806. Alternatively, UPVT can be obtained numerically from the collector efficiency factor F', by dark-measurements with surface temperature measurements, or via FEM methods.

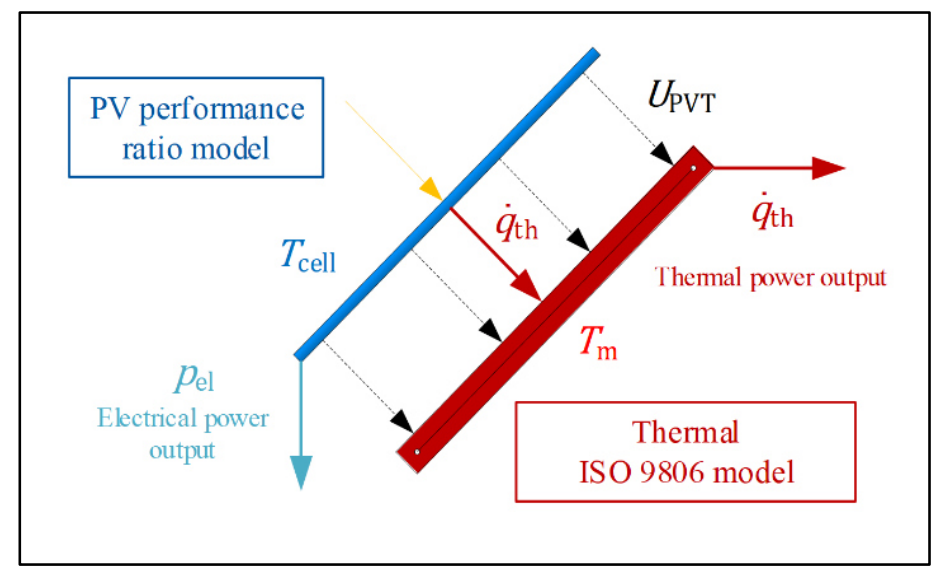

Figure 7: U РVT approach 


\subsubsection{Iterative method}

(Based on contribution by M. Proell)

This method for the determination of the cell temperature $T_{\text {cell }}$ is strongly coupled with the heat fluxes along the collector layers. The cell temperature is determined according to Equation (58):

$$
T_{\text {cell }}=\frac{Q_{\text {Fluid }} \cdot R_{P V}}{A_{P V}}+T_{a b s}
$$

Since the heat flux $Q_{\text {Fluid }}$ is determined considering the effects of the electrical efficiency, which is dependent on the cell temperature $T_{\text {cell, }}$ which is again dependent on the heat flux $Q_{\text {Fluid, }}$, the determination of $T_{\text {cell }}$ has to be determined over an iterative process.

\subsubsection{IEC 60904-5 method}

(Based on contribution by J.-B. Beyssac, C. Schmidt)

This method consists of determining an equivalent cell temperature from open circuit voltage measurements.

$$
T_{E C T}=T_{S T C}+\frac{1}{\beta} \cdot\left[\frac{U_{c o, i}}{U_{c o, S T C}}-1-\alpha \cdot \ln \left(\frac{G_{i}}{U_{S T C}}\right)\right]
$$

Where,

$\begin{array}{lll}T_{S T C} & \begin{array}{l}\text { standardized temperature defined by EN } 61215 \text { to determine } \\ \text { the maximum standard power of a PV module }\end{array} & 25^{\circ} \mathrm{C} \\ G_{S T C} & \begin{array}{l}\text { standardized irradiance defined by EN } 61215 \text { to determine } \\ \text { the maximum standard power of a PV module }\end{array} & 1000 \mathrm{~W} / \mathrm{m}^{2} \\ U C_{0, S T C} & \text { open circuit voltage of a PV module at standard testing } \\ & \text { conditions TSTC and GSTC } & -- \\ U_{C 0, \mathrm{i}} & \text { open circuit voltage measured } & -- \\ G_{i} & \text { Irradiance measured } & --\end{array}$

IEC 60904-5 method requires simultaneous measurement of open circuit voltage and thermal performance. Open circuit voltage measurements shall not disturb the thermal equilibrium of the PVT collectors operating at the Maximal Power Point during ISO 9806 tests. A brief interruption of the load shall be performed at each time step to measure the open circuit voltage.

[U. Fritzsche et al. 2017] proposed a method that considers the mean fluid temperature dependency, the main influencing factor on PVT collectors. The equation is based on the regular equation for thermal performance (52) of unglazed 
or WISC collectors. By changing the sign, the gradient of the cell (absorber) over temperature can be described as follows:

$$
T_{\text {cell }}-\vartheta_{a}=T_{\text {cell, } 0}\left[\eta_{0, h e m}\left(1-d_{u} u\right)+\left(d_{1}+d_{2} u\right)\left(\vartheta_{m}-\vartheta_{a}\right)\right]
$$

Where,

$\begin{array}{ll}\vartheta_{\text {cell }} & \text { Cell temperature } \\ T_{\text {cell, } 0} & \text { Cell temperature conversion point } \\ d_{u} & \text { Wind dependence of the conversion point } \\ d_{1} & \text { Heat gain coefficient } \\ d_{2} & \text { Wind dependence on the heat gain coefficient }\end{array}$

The effects of irradiance are neglected due to the dominating effects of the wind and fluid temperature.

\subsubsection{Determination of electrical yields}

(Based on contribution by A. Gagliano, G. Tina)

There are many different methods that can be employed to determine the electrical power output of a PVT collector. Each of them has certain assumptions and considers the effects of particular conditions on the efficiency of the PV module. Some of these methodologies are presented in the following sub-chapters. The most general equation for the determination of the electrical yields has the following structure:

$$
P_{e l}=\eta_{P V} \cdot G \cdot A
$$

Most authors will agree with this consideration. It is, however, with the determination of the PV efficiency that most of the differences will arise. While some methodologies only consider the effect of the cell temperature, others will consider the effects of reduced radiation, incidence angle or simply present a completely different procedure.

Owing to the possible reduction of global irradiance reaching the absorbers in glazed $\mathrm{PV} / \mathrm{T}$ panels or PVT panels with water that flows in the upper PV surface, the irradiance that strikes the PV cells can be reduced so that in this case, a specific model can be adopted. The following formula is used instead of formula (61)when $G$ is not $>125 \mathrm{~W} / \mathrm{m}^{2}$ [B. Marion 2008].

$$
P_{P}=\frac{0.008 G^{2}}{G_{S T C}} P_{S T C}\left[1-k_{p}\left(T_{c}-T_{S T C}\right)\right]
$$

An additional approach, based on Equation (61), suggests the comparison of the obtained electrical energy in terms of its exergy. Where: 


$$
\dot{E} x_{e l}=P_{e l}
$$

The average exergy efficiency of the electricity production ( $\xi e l)$ can be defined as

$$
\xi_{e l}=\frac{P_{e l}}{E x_{s o l} A_{P V}}
$$

And finally the overall exergy efficiency $\xi$ of the PVT collector is calculated by

$$
\begin{gathered}
\xi_{P V T}=\frac{\dot{E x_{Q}}+P_{e l}}{E x_{s o l} A_{a b s}}=\xi_{t}+P F \xi_{\text {el }} \\
P F=\frac{A_{P V}}{A_{a b s}}
\end{gathered}
$$

However, this has been strongly discouraged within the IEA SHC Task 35 [M. Collins and $\mathrm{H}$. Zondag 2009].

\subsubsection{Temperature effect on the PV efficiency}

(Based on contribution by M. Herrando, M. Proell)

This method considers the effect of temperature, which is of particular importance on PVT collectors, on the PV module efficiency. The equation can be written as follows and is presented by [E. Skoplaki and J. Palyvos 2009] and [D. Evans and L.

Florschuetz 1977]:

$$
\eta_{\mathrm{PV}}=\eta_{\mathrm{ref}}\left[1-\beta \cdot\left(T_{\text {cell }}-T_{\mathrm{STC}}\right)\right]
$$

where $\eta_{\text {ref }}$ is the reference module efficiency at a PV cell temperature, $\mathrm{T}_{\mathrm{STC}}$, of $25^{\circ} \mathrm{C}$ and at a solar irradiance of $1,000 \mathrm{~W} / \mathrm{m}^{2}$ (value given by the manufacturer), and $\beta$ is the temperature coefficient for the PV module. In this methodology, the cell temperature $\mathrm{T}_{\text {cell }}$ is determined with the method presented in Section 0. Alternatively, other methods presented in Section 2.2.1 could be employed.

\section{(Based on contribution by L. Brottier)}

This methodology is an extension of the temperature effect. Additionally, it considers the effects of the irradiation when different to the standard conditions. The equation follows the same structure as Equation $x x$, determining the effects of the reduced irradiation with aid of the coefficient $\mathrm{k}$.

$$
\eta_{\mathrm{PV}}=\eta_{\mathrm{ref}}\left[1-\beta \cdot\left(T_{\text {cell }}-T_{\mathrm{STC}}\right)\right] \cdot\left[1-k\left(G-G_{\mathrm{STC}}\right)\right]
$$

\subsubsection{Temperature and thermal yield effect}

(Based on contribution by N. Pokorny)

Considering the energy balances shown on Section 0 , and also considering the 
temperature effect on the PV efficiency, Equation (69) allows calculating the electrical yields based on multi-node energy balance approach.

$$
P_{e l}=\tau_{g} \cdot A_{a p} \cdot P F_{P V} \cdot \eta_{P V} \cdot\left\{1-\frac{\beta \cdot \eta_{S T C}}{\eta_{P V}} \cdot\left[F_{R} \cdot\left(T_{i n}-T_{a}\right)+\frac{S}{U} \cdot\left(1-F_{R}\right)\right]\right\}
$$

where the photoelectric efficiency $\eta_{P V}$ is estimated as a function of ambient temperature $T_{\mathrm{a}}$ calculated as

$$
\eta_{\mathrm{PV}}=\eta_{\mathrm{ref}}\left[1-\beta \cdot\left(T_{\mathrm{a}}-T_{\mathrm{STC}}\right)\right] \cdot\left[1-k \cdot \ln \cdot\left(\frac{G}{G_{\mathrm{STC}}}\right)\right]
$$

\subsubsection{Estimation based on module characteristics}

(Based on contribution by N. Amrizal)

This methodology considers the electrical characteristics of the cell such as the recombination losses, ideal current, photogenerated current and current losses. One of the main advantages is that the risk of overestimating the cell temperature is reduced.

$$
P_{e l}=\frac{N_{P} N_{S}}{A_{c o l}} \cdot V_{c} \cdot\left(I_{p h}+I_{d}+I_{s h}\right)
$$

Where the diode current is given by:

$$
I_{d}=I_{0} \cdot\left[\exp \left(\frac{V}{n V_{T}}\right)-1\right]
$$

And the terms are considered as follows:

$$
\begin{gathered}
I_{p h}=d_{1} K_{\theta}(\theta)(\tau \alpha)_{e n} G \\
I_{d}=d_{2} \varphi(T)\left[\exp \left(\frac{\left(V_{c}+r_{s} I_{c}\right)}{n V_{T}}\right)-1\right] \\
I_{s h}=d_{3}\left(V_{c}+r_{s} I_{c}\right)
\end{gathered}
$$

The electrical parameterization introduces explicitly the irradiance and temperature dependence of some magnitudes: $I_{p h}, I_{0}$ and $n V_{T}$. The model assumes that the photocurrent generated $I_{p h}$ is proportional to the incident irradiance $G$ and the reverse saturation diode current $I_{0}$ has a thermal dependence of $\varphi(T)$. No temperature dependence of Eg, Iph and Ish is considered.

\subsubsection{Electrical performance ratio model of IEC $61853+U_{\mathrm{PVT}}$ model}


In this method, the effects of three parameters are considered when calculating the overall electrical efficiency. These parameters are the incidence angle, irradiance and cell temperature. Compared to the previously mentioned methods, this is the only that considers the effects of the incidence angle, while also considering the effects of the irradiance and cell temperature.

The overall electrical efficiency $\eta_{e l}$ is calculated with:

$$
\eta_{\mathrm{el}}=\eta_{\mathrm{el}, \mathrm{ref}} \cdot P R_{\mathrm{tot}}
$$

The electrical power output of the PVT collector $\mathrm{P}_{\mathrm{el}}$ is given by:

$$
P_{\mathrm{el}}=\eta_{\mathrm{el}, \mathrm{ref}} \cdot P R_{\mathrm{tot}} \cdot G \cdot A_{\mathrm{PVT}}
$$

and as specific electrical power output by [M. Lämmle et al. 2017]:

$$
p_{\mathrm{el}}=\eta_{\mathrm{el}, \mathrm{ref}} \cdot P R_{\mathrm{tot}} \cdot G
$$

where $\eta_{\text {el,ref }}$ is the electrical efficiency at reference conditions (usually STC conditions), $\mathrm{PR}_{\text {tot }}$ is the overall instantaneous performance ratio, $\mathrm{G}$ the global radiation on PVT plane and $\mathrm{A}_{\mathrm{PVT}}$ the PVT collector area.

The overall instantaneous performance ratio is calculated with [M. Lämmle et al. 2017]:

$$
P R_{\text {tot }}=P R_{\mathrm{IAM}} \cdot P R_{\mathrm{T}} \cdot P R_{\mathrm{G}}
$$

The electrical performance model takes into account the following loss effects (performance ratios PR):

- Loss effects of incidence angle $P R_{\mathrm{IAM}}$

- Loss effects of irradiance $P R_{\mathrm{G}}$ and

- $\mathrm{PV}$ cell temperature dependence of electrical efficiency $P R_{\mathrm{T}}$.

\section{Loss effects of incidence angle}

The instantaneous performance ratio due to incidence angle losses $P R_{\mathrm{IAM}}$ is calculated with [J. Duffie and W. Beckman 2013]:

$$
P R_{\mathrm{IAM}}=1-b_{0, \mathrm{el}} \cdot[1 / \cos (\theta)-1]
$$

where $b_{0, \mathrm{el}}$ is the constant for electrical IAM and $\theta$ the incidence angle of beam radiation. 


\section{Loss effects of irradiance}

The instantaneous performance ratio due to irradiance losses $P R_{G}$ is calculated with [W. Heydenreich et al. 2008]:

$$
P R_{\mathrm{G}}=a \cdot G+b \cdot \ln (G+1)+c \cdot\left[(\ln (G+\mathrm{e}))^{2} /(G+1)-1\right]
$$

with the model parameters a in $\mathrm{m}^{2} \mathrm{~W}-1, \mathrm{~b}$ and $\mathrm{c}$ dimensionless, the global irradiance $\mathrm{G}$ in $\mathrm{W} \mathrm{m}-2$ and the Euler's number e.

\section{PV cell temperature dependence of the electrical efficiency}

The PV cell temperature dependence of the electrical efficiency is calculated with [E. Skoplaki and J. Palyvos 2009]:

$$
P R_{\mathrm{T}}=1-\beta \cdot\left(T_{\text {cell }}-T_{\text {ref }}\right)
$$

where $\beta$ is the power temperature coefficient of the PV cells, $T_{\text {cell }}$ the temperature of the PV cells and $\mathrm{T}_{\text {ref }}$ the PV cell temperature at reference conditions (usually STC conditions).

The IAM parameter $\mathrm{b}_{0, \mathrm{el}}$ can be either identified by a parameter identification process with measurements or set equal to the thermal IAM $b_{0, t h}$. The electrical parameters $\eta_{\text {el,ref, }} \beta$ and the irradiance-dependent parameters $a, b$ and $c$ are obtained from the datasheet of the PV module, based on performance measurements according to standard.

This model, including the analytical model with reduced complexity to determine the PV cell temperature from 2.2.1.3 and a mode to use the PV cell temperature as direct model input, is implemented in TRNSYS Type 835 [D. Jonas 2018a] and can be connected to the thermal ISO 9806 TRNSYS model Type 832 [M. Haller et al. 2013]. $A$ validation of the model is presented in [D. Jonas et al. 2018b].

\subsubsection{Simultaneous parametrization}

\section{Based on contribution by C. Schmidt)}

These methods essentially represents an extension of the quasi-dynamic method [ISO 2013] [K. Kramer and H. Helmers 2013]. The extension consists of simultaneously characterizing the electrical $\mathrm{P}_{\mathrm{el}}$ and thermal $\dot{\mathrm{Q}}$ performance of PVT collectors on the basis of a quasi-dynamic measurement on an external test bench. By doing that, the thermal coupling of cell temperature and fluid temperature is inherent in the measurement data. Even though it is like a black box, meaning the coupling has to explicit value or parameter in the end, the performance of the collector can be most representatively described for any other operating temperature on both, the electrical and the thermal energy output. 
The electrical power can be calculated using Equation (80). The main influencing factors for the electrical efficiency were derived from a two-node model. As with ISO 9806:2013 QDM, the values for individual model parameters are identified by multilinear regression.

$$
\frac{P_{e l}}{A_{r e c}}=\frac{P_{e l}}{A_{r e c}}=b_{0} G_{C}-G_{C}\left(b_{1} v_{m}+b_{2} v_{a}\right)-b_{3} G_{C}^{2}
$$

This method is promising but has not been evaluated in all technical variants of PVT yet. On-going research is applying and modifying the method towards an easy to handle versatile approach. 


\subsection{Impact on market development}

The young market of PVT collectors is volatile in market contributors and product developments. Also the steering instruments of the established solar thermal policies and PV policies are under revision taking into account the "new kid on the block" i.e. the PVT new comer. The situation is changing rapidly and hard to survey. The report thus wants to provide some guidance wherever possible by sharing information.

\subsubsection{Rating and Certification}

One important marketing factor is the possibility to compare a new product with the existing products in the market. For PVT collectors this is twofold; on the one side they are compared against Solar Thermal collectors and systems, on the other side against PV modules and fields.

For the existing products they compete with some certification schemes that are already established. One could call them mandatory, even though they are volunteer due to their deeply penetrated market impact [K. Kramer and H. Helmers 2013].

For Solar Thermal Collectors and Systems, the Solar Keymark Label [ESTIF/Solar Keymark Label] is the most relevant Certification scheme in Europe. In North America, one will find [IAPMO] and [SRCC] (http://solar-rating.org) relevant. In China, the Golden Sun Label [CGC] and in Oceania the Standard Mark [SAE] is well known. Just to mention that there are a lot of national and regional labels, partly overlapping, partly extending the mentioned schemes, which cannot be discussed here (more information on [ESTIF Country Reports]).

For the Solar Thermal market, the labels apply in detail different ways of presenting the test results, yields and ratings. What the most relevant schemes have in common though, is that they use the results generated by applying the methods defined in ISO 9806 [ISO 2017]. This provides the great chance to qualify PVT collectors with the same instruments. Strategically this is highly recommended because the market is yet too small and the players to week to set up a parallel rating scheme only for PVT.

The consequence from this analysis is the need to double check shortcomings regarding the specifications within the existing standard, respectively the certification schemes for PVT. On the other hand, it is essential to use the existing basis to the most to characterize PVT collectors, which basically means that the ISO 9806 [ISO 2017] shall be applied for thermal performance characterization of PVT modules.

Shortcomings in the schemes shall be reported to the existing working groups of the schemes (find contacts on the homepages) and the Standardization Committees ISO TC180 "Solar Energy" [ISO/TC 180] respectively. For example:

- The efficiency value given for Energy Label Rating on the second page of the Solar Keymark data sheet is calculated at $50^{\circ} \mathrm{C}$. This is not a useful operation point for a system integrated solution of a WISC PVT collector. The value therefore does not well represent the energy contribution such collectors can provide. This is an un-fair bias. 
- A scaling of the PV modules power can influence the thermal performance. How can a family of PVT products still be defined or qualified for the thermal part in one pass, to avoid endless testing efforts?

For the PV part the situation is similar. The different rating and certification schemes are national based but also there is a commonly accepted IEEE rating scheme.

IEC 60904 provides the methodology to parameterize the performance output of PV modules.

For PV modules this is a standard procedure. In the case that the PVT product is built without an existing PV performance characterization, the PVT product shall be characterized accordingly.

- In covered PVT collectors a flashing procedure is of course not possible any more after the mounting of the PV laminate into the collector box. The PV output is nevertheless reduced by adding the cover sheet (glass, foil, polymer) as a cover of the collector box. This is not described in the test procedures yet. Either one flashes before, and accepts the over rating, or one tries to generate the electrical performance characteristics during the operating condition.

- In concentrating PVT collectors, the concentrating geometry is influencing the homogeneity of the radiation on the PVT absorber, also sometimes a flashing of the "pure" PVT absorber is not doable. Sometimes the PVT laminate can be bi-facial where there is not even a clear testing standard in IEC yet.

\subsubsection{Processability}

Another important marketing factor is the "processability" or usability of technical characteristic in simulation tools (Polysun, Tsol, trnsys, Modelica, SCenoCalc, ...). For the buying decision, often planning process and tenders are set. To calculate the relevant yields and cost, savings and return of invest figures, it is essential to provide the technical product characteristics in an easy to process way. Individual calculation tools do often not find a high acceptance in competitive tenders or with bigger investors and turn-key providers. An individual third party planning by universities or research agencies, which could contribute to the acceptance, are often too expensive and time consuming. Therefore, the recommendation is to work towards an integration into existing tools which are already market relevant.

For the solar thermal characteristics, this means that we recommend to provide the ISO 9806 collector parameters.

For the PV characteristics we recommend to provide the

- peak efficiency and the

- temperature coefficient (W/K).

\subsubsection{Costs}

As mentioned above, the niche market of PVT is volatile. This in consequence means that products entering the market often have to go through modifications already after some months or short years. Every modification of the products has potential consequences in testing (see chapter 3.1.1). To base PVT testing, as much as possible on the existing testing schemes for PV and ST, is therefore essential to 
lower individual consultation efforts, discussions, back-and-forth scenarios and so on. Our recommendation is not to skip relevant test though to save some money. Experience shows that the complications of problems occurring later are costing much more to be solved.

Highly specific and exclusive methods are normally only provided by one or two institutions. Therefore, there is a risk of pricing high the rare service.

Accredited test laboratories have to have a clear and non-negotiable pricing, through which the accreditation makes sure that every costumer is treated and serviced equally. Besides the necessity resulting from certification to visit an accredited test lab this is another strong argument.

Experienced labs in Europe show testing costs of:

- Testing of existing PV along with new PVT costs around 10,000 $€$ for ST and around $20,000 €$ for PV.

- Testing of all new collectors costs $10,000 €$ for ST and around $50,000 €$ for PV.

- Re-Testing modifications of an existing tested PVT is depending on the specific effort, but below those values.

\subsubsection{Suitability}

Testing has many goals. One purpose is to provide input for the economic and technical key performance indicators (KPIs). For PVT the challenge is to some extent, that the KPIs are not yet mature and settled in the market. Different market participants try to position their product using different KPIs, some of which are quite made-up and hard to trace back to any technical value with some consistent references. Therefore the Task 60 has a deliverable on KPIs for PVT (see relevant publication on the Task 60 web site).

In this report we just mention that the technical characteristics to describe the product shall be giving relevant input to be able to calculate market relevant KPIs for the product itself, as well as at the system level.

The KPIs to be expected are:

- costs $€ / \mathrm{kWh}$,

- solar fraction achieved,

- coefficients of performance known as COPs,

- warranties of performance over time,

- energy labelling of a system.

\subsection{Precision of equation model and accuracy}

To discuss the relevance of precision in a methodological approach is complicated but necessary. Basically one can say, that the more precise a technical understanding and characteristics shall be, the more effort generates to derive it. The decision is therefore quite directly connected to the cost/value ratio. PVT collectors can be operated in quite a wide range of operation modes, depending on the system approach they are operated in. This has been described in chapter 1. Deriving characteristics of those operating modes requests results to be able to adequately 
describe all possible operating modes in a representative and fairly precise way. As a consequence, some of the methods shown in chapter 2 provide solutions. approaches and ideas on how to describe specific features of a PVT collector in some extraordinary operating modes.

The following questions arise from this situation:

- Which precision is needed?

- Which operating mode is relevant enough to get the KPIs (see chapter 3.1.4) and to spent extra effort on?

- What precision can be reached on which effect?

To answer and discuss those questions a kind of Delphi-Method approach was chosen. A matrix with rating of the effect of condensation and Icing (column blue) and below ambient (column green) was provided to the Task members. The sent back ratings were averaged and colour-coded, to give a quick and easy impression what is seen necessary to put further effort into. The research questions derived from this survey are listed in chapter 4.

Preliminary recommendations can be formulated based on this survey too.

Icing and Condensation are not specifically identified by a parameter for each PVT product, but fixed to a $q_{\mathrm{cond}}=+5$ to $+10 \%$ increase of power from collector, when the temperature is below the dew point (tipping point between $T_{m}$ and $T_{\text {dew }}$ ) in every time step. This can be implemented in every simulation tool and calculated for relevant installations.

Night cooling is ignored.

Thermal performance above and below ambient is important. It is possible to include steady state performance at a set of mean collector temperatures starting below ambient, which may be even segmented by sub-categories of collectors (e.g. concentrating collectors may need testing at higher temperatures, but these could be ignored for more common PVT collectors). The ISO 9806 standard solves this by advising to test the thermal performance at least at three evenly distributed mean collector fluid temperatures over the operation range.

Also, as some PVT collectors intentionally reject energy in a cooling mode, either at temperatures above ambient or radiating to the night sky temperature, it would be helpful to have technical characteristics for this alternate operating mode (e.g. at PVT mean fluid temperature $5^{\circ} \mathrm{C}, 12^{\circ} \mathrm{C}, 19^{\circ} \mathrm{C}, 30^{\circ} \mathrm{C}$ towards sky temperature of $-20^{\circ} \mathrm{C}$, $5^{\circ} \mathrm{C}, 15^{\circ} \mathrm{C}, 20^{\circ} \mathrm{C}$ ). At present, this measurement is not described in a standard, and the details for a representative, repeatable, validated and un-biased method to test different products against is missing.

For the Solar Keymark performance, Task 60 believes we need a few different operating points to cover the range of applications. As an example: heat pump 
source (up-to $\left.-20^{\circ} \mathrm{C}\right)$, space cooling $\left(18^{\circ} \mathrm{C}-12^{\circ} \mathrm{C}\right)$, space heating $\left(35^{\circ} \mathrm{C}\right)$, domestic hot water heating $\left(50^{\circ} \mathrm{C}\right)$, process heating $\left(80^{\circ} \mathrm{C}-200^{\circ} \mathrm{C}\right)$.

It is well known that condensation is a phenomenon that can occur in cold areas, but also in areas characterized by a relatively high humidity level. In fact, the radiation heat loss can allow the temperature of the collector glazing to reach the dew-point of the surrounding, determining the development of condensation on the glazing.

This latter represents a crucial issue and its effect, in term of PVT collector durability and thermal performance, vary according to the PVT collector type. From both tables below, it can be seen that for PVT flat plate collector, the rating of condensation effect results to be moderately important in each application. In fact, the condensation can significantly reduce the PVT collector thermal performance, as a huge quantity of energy can be wasted in order to evaporate the moisture. Moreover, the moisture infiltration can damage the collector absorber. Compared with the PVT flat plate collector, in the PVT evacuated tubular one, the rating of the condensation effect in both locations results to be not important. As a matter of fact, vacuum tube collectors are hermetically sealed and cannot be subject to condensation. Conversely, regarding unglazed WISC PVT collectors (uninsulated/insulated), the rating of condensation effect appears to be significant, as they can collect useful heat by condensation, which is transferred to the circulating fluid and can be used as second heat source when connected in series with a heat pump.

Another advantage deriving from the combination of the heat pump with a WISC PVT collector, is that the operating range of the solar collector can be shifted to temperature levels that are below the ambient. Obviously by sending the absorbed solar irradiation to the evaporator side of the heat pump, the collector can make the heat pump operate at lower temperature, thus increasing its overall efficiency. Conversely, when a WISC PVT collector operates together with a heat pump under extreme weather conditions, the rating of icing effect represents a crucial aspect. The possible frost formation on the external heat exchanger of the heat pump can act as a thermal insulation by reducing the heat transfer rating between the outdoor air and the evaporator. Moreover, the ice can increase the air-side pressure drop, due to the reduction of the airflow passage, degrading the heat pump performance.

Therefore based on this analysis, more efforts should be put on:

- Extend the modelling capabilities of current available WISC PVT collectors models, in order to be able to evaluate accurately the influence of condensation gains and icing on the heap pump system performance.

- Validate the models. 


\section{Climate Sweden :}

\begin{tabular}{|c|c|c|c|c|c|c|c|c|c|c|}
\hline $\begin{array}{c}\text { Product } \\
\text { Type }\end{array}$ & \multicolumn{2}{|c|}{$\begin{array}{l}\text { WISC PVT } \\
\text { uninsulated }\end{array}$} & \multicolumn{2}{|c|}{$\begin{array}{l}\text { WISC PVT } \\
\text { Insulated }\end{array}$} & \multicolumn{2}{|c|}{$\begin{array}{l}\text { PVT Flat Plate } \\
\text { Collector }\end{array}$} & \multicolumn{2}{|c|}{$\begin{array}{l}\text { PVT Evacuated } \\
\text { tubular Collector }\end{array}$} & \multicolumn{2}{|c|}{$\begin{array}{c}\text { PVT } \\
\text { Concentrating } \\
\text { Collector }\end{array}$} \\
\hline Application type & I & II & I & II & 1 & II & I & II & I & II \\
\hline HP Source serial & 3 & 3 & 3 & 2 & 2 & 1 & 1 & 1 & 1 & 1 \\
\hline $\begin{array}{l}\text { HP Source and } \\
\text { Parallel }\end{array}$ & 3 & 3 & 3 & 2 & 2 & 1 & 1 & 1 & 1 & 1 \\
\hline $\begin{array}{l}\text { HP Source, } \\
\text { parallel \& } \\
\text { regeneration }\end{array}$ & 3 & 3 & 3 & 2 & 2 & 1 & 1 & 1 & 1 & 1 \\
\hline Swimming pools & 3 & 2 & 2 & 1 & 2 & 1 & 1 & 1 & 1 & 1 \\
\hline DHW & 2 & 1 & 2 & 1 & 2 & 1 & 2 & 1 & 2 & 1 \\
\hline DHW and Heating & 1 & 1 & 1 & 1 & 2 & 1 & 1 & 1 & 1 & 1 \\
\hline Process Heat & 1 & 1 & 1 & 1 & 1 & 1 & 1 & 1 & 1 & 1 \\
\hline
\end{tabular}

\section{Climate Qatar:}

\begin{tabular}{|c|c|c|c|c|c|c|c|c|c|c|}
\hline $\begin{array}{l}\text { Product } \\
\text { Type }\end{array}$ & \multicolumn{2}{|c|}{$\begin{array}{l}\text { WISC PVT } \\
\text { uninsulated }\end{array}$} & \multicolumn{2}{|c|}{$\begin{array}{l}\text { WISC PVT } \\
\text { Insulated }\end{array}$} & \multicolumn{2}{|c|}{$\begin{array}{l}\text { PVT Flat Plate } \\
\text { Collector }\end{array}$} & \multicolumn{2}{|c|}{$\begin{array}{c}\text { PVT } \\
\text { Evacuated } \\
\text { tubular } \\
\text { Collector }\end{array}$} & \multicolumn{2}{|c|}{$\begin{array}{c}\text { PVT } \\
\text { Concentrating } \\
\text { Collector }\end{array}$} \\
\hline Application type & I & II & I & II & I & II & I & II & 1 & II \\
\hline HP Source serial & 3 & 3 & 3 & 3 & 2 & 2 & 1 & 1 & 1 & 1 \\
\hline $\begin{array}{l}\text { HP Source and } \\
\text { Parallel }\end{array}$ & 3 & 3 & 3 & 3 & 2 & 2 & 1 & 1 & 1 & 1 \\
\hline $\begin{array}{l}\text { HP Source, } \\
\text { parallel and } \\
\text { regeneration }\end{array}$ & 3 & 3 & 3 & 3 & 2 & 2 & 1 & 1 & 1 & 1 \\
\hline Swimming pools & 2 & 2 & 2 & 2 & 2 & 2 & 1 & 1 & 2 & 2 \\
\hline DHW & 2 & 2 & 2 & 1 & 2 & 2 & 1 & 1 & 2 & 2 \\
\hline DHW and Heating & 2 & 1 & 2 & 1 & 2 & 1 & 1 & 1 & 2 & 1 \\
\hline Process Heat & 2 & 1 & 1 & 1 & 2 & 1 & 1 & 1 & 2 & 1 \\
\hline
\end{tabular}

Table 1: Best applications for PVT collectors in two very different climates

* The numbers I (operating temperature below dew and freezing point) and II (operating temperature below ambient) correspond to the operating conditions from Figure 1; Rating 1, 2 and 3 with $1=$ not important and 3=important 


\section{Conclusion on Performance Characterization Methodology}

Following listing summarizes the findings in no particular order :

1) Thermal performance characterization for the T part of a PVT collector shall be done according to ISO 9806 .

2) The performance value shall be given at the same wind speed (ISO standard reporting conditions asks for $1,3 \mathrm{~m} / \mathrm{s}$ ).

3) There is a clear limitation of the ISO 9806 for night cooling effects.

4) Same is true for operating conditions below ambient temperature performance, which would be helpful to overcome.

5) For the schemes SRCC and Solar Key Mar: specific working groups currently handle in detail the requirements of PVT. Further input, questions and wishes shall therefore be handed over as soon as possible to these working groups and a personal engagement into those groups is recommended. Though the basic principle of mutual acceptance manifested in the Global Solar Certification Network (GSCN) is valid, national rules for the electrical safety prevail.

6) For the PV part of certification, it is recommended that the process is started with contacting the NCB to clarify the needed efforts.

7) Accredited test laboratories are a must for the certification testing. Some have experience with testing PVT, some not. Task 60 recommends discussing the details in a pre-feasibility study with the selected laboratories to avoid disappointing/ misleading contracting. For the PV characteristics, Task 60 recommends to provide the information according to IEC 61215.

8) The electrical safety of a PVT collector has to been tested according to IEC 60730.

9) To save costs for testing and certification, Task 60 recommends checking all parts of the PVT along temperature requirements. Underestimation of possible occurring temperatures in some components is still the major reason of failure of solar collectors.

10) Task 60 recommends clustering modifications in product generations not shorter than one year, to have a maximum re-testing frequency of one re-test (eventually partial testing) a year. So as to minimize testing cost.

11) For fair market comparisons, Task 60 recommends the following KPIs to be considered at system level, but calculated based on real data obtained from standardized testing results of the collectors and/or the system:

a. Collector Annual Output (CAO) @ $5^{\circ} \mathrm{C}, 15^{\circ} \mathrm{C}, 25^{\circ} \mathrm{C}, 50^{\circ} \mathrm{C} 75^{\circ} \mathrm{C}$ (SCenoCalc Keymark Certificate),

b. PV output (in alignement with SCEnoCalc Conditions),

c. Levelized Cost of Heat ( $\mathrm{LCOH})$ in $\mathrm{cts} / \mathrm{kWh}$

d. Levelized Cost of Electricity (LCOE) in cts/kWh 


\section{List of research questions}

Along the 3 years of Task 60, experts have been discussing PVT collectors testing intensively. Since the technology is still new for a new generation of products, open questions remain.

Here is a list of questions that future research should address according to Task 60:

1. How should it be handled that ambient energy and solar energy are described in one "coordinate" system?

2. Is there a need to investigate electrical performance changes of PVT over time?

3. How important are the thermal stresses/strains due to PVT collector heating/cooling on the PV cells? Does this affect the PV cells performance over time?

4. Is the temperature coupling of electrical yield to collector operating temperature addressed in the existing marketing instruments of PVT manufacturers?

5. Yearly gain prediction should be the target. What kind of tool is best suited for PVT simulations?

a. Can ScenoCalc be extended for different temperature levels?

b. How to handle in simplified models the coupling or dependency of $Q_{\text {th }}$ and $\mathrm{W}_{\mathrm{el}}$ ?

6. How should the solar heat source in heat pumps be calculated within the wellknown method called ErP?

7. How night cooling for example with WISC PVT collectors compared with other cooling technics?

8. How can the performance of thermodynamic systems be evaluated using PVT as direct/indirect evaporator of a heat pump including self-consumption of the electricity in a standard way?

9. How do WISC PVT collectors perform at $\mathrm{T}_{\text {char }}=0 \ldots 15^{\circ} \mathrm{C}$ when water condensation can occur? How important is the effect in different climates? What is the impact on the collector lifetime? 


\section{Function Test, Reliability, Serviceability, Durability and Accelerated Aging Test}

Besides the performance characterization, some essential question is of course linked to the products serviceability and durability which will consequent in performance guaranties, time of warranties and quality promises. To derive the basis from experimental testing and theoretical design approaches, it is again interesting to have an indication of the relevance of each risk or influence factor. For this purpose, in a classical product design process, a so called FMEA (Failure Mode and Effect Analysis) analyses might be done when relevant. From such analysis the most critical boundaries of a product can be identified. For Solar Thermal collectors as well as for PV modules, this is quite a standard of the industry in most countries. For PVT there are some new "risks" embedded, which result from the combination of the electrical and the thermal solar energy conversion. Also, in-depth understanding is widely missing, although for some manufacturers there have been already projects dealing with this.

\subsection{Certification, Market Access and Legally Mandatory Test}

Similarly to the described set of standards for the performance test in chapter 3 , for reliability testing and accelerated aging testing, methods do exist or are under development. For the Solar thermal part again, the same certification schemes apply. For example, the Solar Keymark scheme is asking for a full approved testing according ISO 9806 (see also: Guideline to ISO 9806 of Task 57), which means that a given serviceability test has to be approved (see Figure 8).

For the electrical side, there is an IEC 61215 (crystalline PV tech) respectively IEC 61646 (thin film PV tech) standard. Those standards are defining reliability tests representing typical operating conditions of PV modules. The tests are volunteer but also well established in the market. To some good extent, the results from those tests allow a manufacturer to define the product warranty and understand the risks before entering the product into the sale process.

Testing and certifying PV Modules is respecting the electrical safety requirement. In Europe, this results in applying the Low Voltage Directive of the EU. With this the consequence is to test the product against the [IEC 61730] standard and bypassing those tests declaring the safety of the module. This is mandatory also for PVT collectors. 


\begin{tabular}{|c|c|c|c|c|c|}
\hline ㄴㅗㅗ & 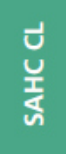 & 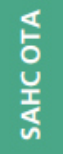 & 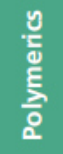 & 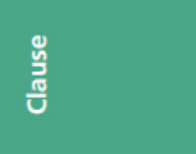 & 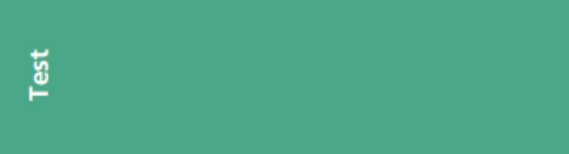 \\
\hline- & $\checkmark$ & - & $\Delta$ & Clause 7 & Air Leakage Rate Determination \\
\hline- & $\Delta$ & $\Delta$ & $\Delta$ & Clause 8 & Rupture and Collapse Test \\
\hline$\Delta$ & $\Delta$ & $\Delta$ & $\triangle$ & Clause 9 & Standard Stagnation Temperature Determination \\
\hline$\checkmark$ & $\checkmark$ & $\checkmark$ & $\checkmark$ & Clause 10 & Exposure Test \\
\hline$r^{1}$ & $v^{1}$ & $v^{1}$ & $v^{1}$ & Clause 11 & External Thermal Shock Test \\
\hline$\checkmark$ & - & - & $\checkmark$ & Clause 12 & Internal Thermal Shock Test \\
\hline$\checkmark$ & $\checkmark$ & $\checkmark$ & $\checkmark$ & Clause 13 & Rain Penetration Test \\
\hline$\sqrt{2}$ & - & - & $\sqrt{ }^{2}$ & Clause 14 & Freeze Resistance Test \\
\hline$\checkmark$ & - & - & $\triangle$ & Clause 6 & Internal Pressure Test for Fluid Channels \\
\hline$(\checkmark)$ & $(\checkmark)$ & $(\checkmark)$ & $(\checkmark)$ & Clause 15 & Mechanical Load Test \\
\hline$(\checkmark)$ & $(\checkmark)$ & $(n)$ & $(\checkmark)$ & Clause 16 & Impact Resistance Test \\
\hline$\checkmark$ & $\checkmark$ & $\checkmark$ & $\checkmark$ & Clause 17 & Final Inspection \\
\hline$\checkmark$ & $\checkmark$ & $\checkmark$ & $\checkmark$ & Clause $19-26$ & Thermal Performance Test \\
\hline$\checkmark$ & $\checkmark$ & $\checkmark$ & $\checkmark$ & Clause 27 & Pressure Drop Measurement \\
\hline
\end{tabular}

Figure 8: Test overview (Mehnert et al. 2018)

Where, $\checkmark$ mandatory, $\checkmark^{1}$ only for collectors without toughened glass, $\checkmark^{2}$ only for collectors claimed to be freeze resistant and collectors containing heat pipe, $(\checkmark)$ mandatory but the manufacturer can define the maximum load to be zero, - not mandatory or not possible, $\triangle$ mandatory and under SSC (Standard Stagnation Conditions; clause 9).

SLHC

SAHC CL

SAHC OTA

Solar Liquid Heating Collector

Polymerics

Solar Air Heating Collector with Closed Loop operation

Solar Air Heating Collector with Open To Ambient operation

collectors in which organic materials are used for fluid channels

thereby being exposed to high temperatures and

pressures respectively

As a lot of PVT products are started with an existing PV module which might have been tested and is therefore already approved, there is a possibility to shortcut the testing for the PVT collector by re-using parts of the tests. The decision which test results are still representative for the PVT collector after modifying the original PV module is made by the relevant national certification body (NCB). As a good orientation guideline, the so called "Re-Testing Guidelines" (IEC TS 62915:2018) are often used to go through test by test and argument the necessity of repetition or argument for an acceptance.

In addition, there are overlaps in the boundaries of PV modules and ST collectors. Therefore, for PVT the possibility should be checked, which testing methods are applied similarly from the IEC and the ISO standard and could be potentially merged. The project "PVTNorm" [Fraunhofer ISE] analysed their potential in 2013-2014. Some summarizing excerpts are shown in the following [TÜV Rheinland 2010]: 


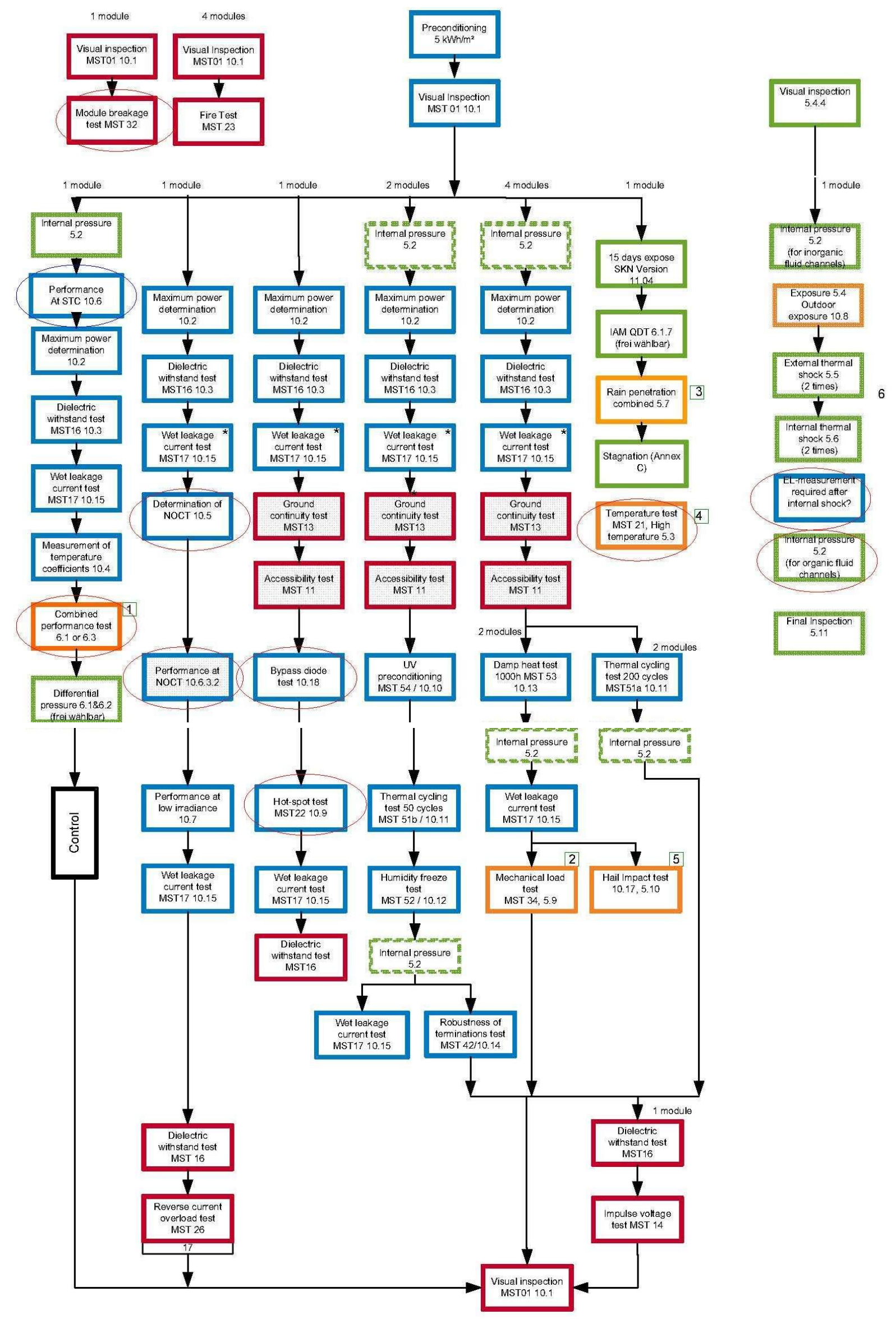

Figure 9: Testing sequences according to IEC (left) and ISO standard (Right). The circled tests were analysed for specific modification towards PVT. [TÜV Rheinland] 


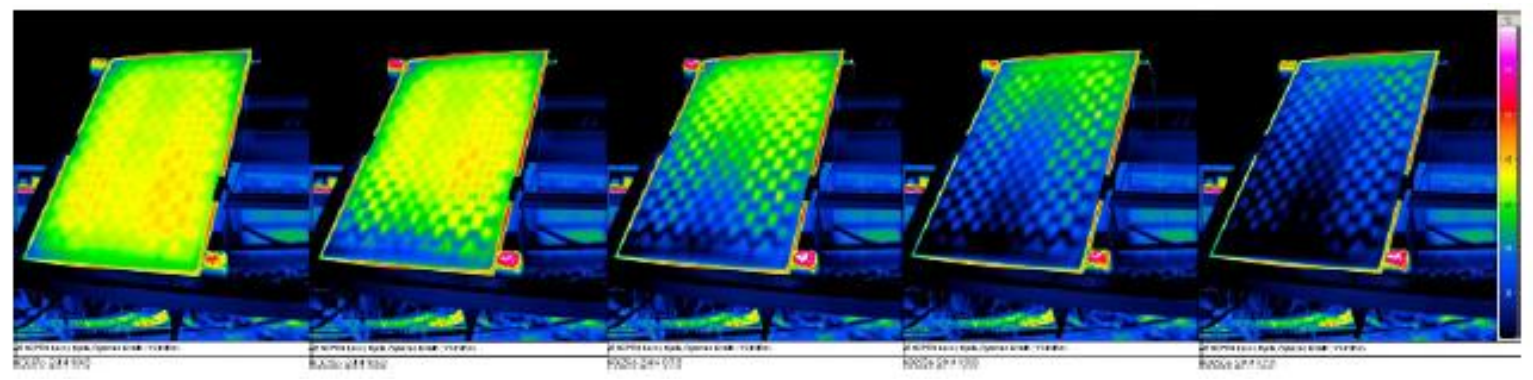

Figure 10: Picture series of a thermal internal shock test according ISO 9806 filing an overheated PVT collector with cold fluid. [Fraunhofer ISE]

On top of this PVT specific information a deeper understanding on aging effects for solar thermal collectors is generated: [DURASOL], [LNEG], [Speedcoll], [Speedcoll2].

The re-testing guidelines are nevertheless not adapted for the specific case of being applied in the context of PVT. Therefore, it is necessary for PVT experts to get involved in the relevant standardization committee [IEC TC 82] to discuss relevant shortcomings. As for example:

- Higher operation temperatures are to be expected for the back-side material, the connection box and maybe the lamination materials. Those materials are judged against their data sheet characteristics. Those again were normally determined by tests in the expected temperature range of a "pure" PV module. The materials often can withstand higher temperatures though. The material checked should therefore also include information from parts suppliers stating higher MRI values.

- For the use of PV modules, it is essential to check their temperature suitability up-front before using them in PVT collectors.

It is recommended that the testing process is started with contacting the NCB to clarify those testing efforts.

A short overview on the decision path is given in the following diagram: 
(A)

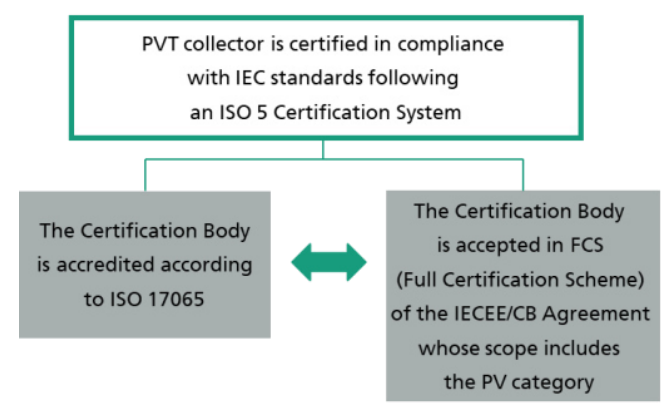

(B)

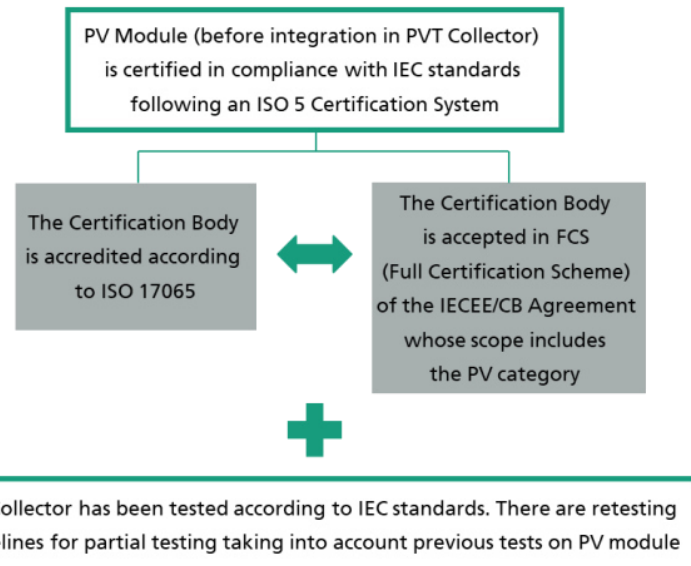

The laboratory is accredited according to ISO 17025 and recognized within the IECEE as CBTL. The following guidelines for partial testing may be used: CTL decision sheet DSH0647A:2010, CTL decision sheet DSH0770:2010, CTL decision sheet DSH0778:2010

Figure 11: What to do to certify your PVT product [Fraunhofer ISE]

\subsection{Warranty and Differentiation of PVT products}

How long will the product last? When is the performance going down and is there a threshold that can be warranted? If the product has a malfunction, can it cause danger and risks or is it just not in service anymore until it can be replaced. This report gives an overview on existing tests which can answer specific questions. At the end it also is identified which gaps of testing Methodology still exist.

The PVT buyer will certainly rely on manufacturer documents but should also ask for certified bodies analyses to have independent information.

Ageing tests of PVT will be the same as for PV or ST modules. They should be run and looked at or translated into the warranties given.

Differentiation between products is often not a matter of energy performances but more of reliability and lifetime.

Testing of products and optimisation from test results is a good way to achieve differentiation. PVT is no exception. 


\section{Conclusion on Reliability Testing Methodology}

Reliability is essential for a sustainable market development of PVT technology, but the quality of products currently offered is variable. On the one hand side, the warranties of existing PV modules set equally high consumer expectations in regard to PVT collectors. On the other hand side, it is not self-evident to assume the durability of PVT is the same as for the PV module it is made with.

The reliability and durability of PVT modules are especially challenged at elevated temperatures and higher humidity loads. The test methods available from the IEC and ISO standards are covering the specifics of PV and ST module's, most of which are similar for PVT modules, too.

Yet, the PVT specific load collectives and the operating conditions arising from the system integration of PVT are only partially covered in the set of existing standards (e.g. stagnation temperature approval, mechanical load resistance).

For now, the state of the art would be to test PVT modules according to the existing standards.

In order to achieve a sustainable market development, it would be helpful to further evaluate all of the PVT specific effects and find answers to the related research questions Task 60 has raised.

We hope Task 60 has paved the way for this development through this report. 


\section{References}

ADAM, M., RADOSAVLJEVIC, R., AND WIRTH, H. 2015. Verbundprojekt: Standardisierung und Normung von multifunktionalen PVT Solarkollektoren (PVT-Norm) :

Teilvorhaben PVT-Systemanwendungen und Simulationen : Laufzeit: 01.02.201331.07.2014.

AGARWAL, R.K., AND GARG, H. 1994. Study of a photovoltaic-thermal systemThermosyphonic solar water heater combined with solar cells. Energy Conversion and Management 35, 605-620.

AMRIZAL, N., CHEMISANA, D., AND ROSELL, J. 2013. Hybrid photovoltaic-thermal solar collectors dynamic modeling. Applied Energy 101, 797-807.

ANTONANZAS, J., DEL AMO, A., MARTíneZ, A., BAYOD, A., AND ANTONANZAS, F. 2015. Towards the optimization of convective losses in photovoltaic-thermal panels. Solar Energy 116, 323-336.

ARGIRIOU, A., SANTAMOURIS, M., AND ASIMAKOPOULOS, D. 1994. Assessment of the radiative cooling potential of a collector using hourly weather data. Energy 19, 879-888.

BERTRAM, E., SCHEUREN, J., GLEMBIN, J., AND ROCKENDORF, G. 2010. Condensation Heat Gains on Unglazed Solar Collectors in Heat Pump Systems. In EuroSun 2010 Conference Proceedings. International Conference on Solar Heating, Cooling and Buildings. ISES Europe; IEA Solar Heating \& Cooling Programme.

BHATTARAI, S., OH, J.-H., EUH, S.-H., KAFLE, G., AND HYUN KIM, D. 2012. Simulation and model validation of sheet and tube type photovoltaic thermal solar system and conventional solar collecting system in transient states. Solar Energy Materials and Solar Cells 103, 184-193.

BIANCHINI, A., GUZZINI, A., PEllegrinI, M., AND SACCANI, C. 2017. Photovoltaic/thermal (PV/T) solar system: Experimental measurements, performance analysis and economic assessment. Renewable Energy 111, 543-555.

BunEA, M., PERERS, B., EICHER, S., HILDBRAND, C., BONY, J., AND CITHERLET, S. 2015. Mathematical modelling of unglazed solar collectors under extreme operating conditions. Solar Energy 118, 547-561.

CGC. China Quality Certification Centre. http://www.cgc.org.cn.

CHOW, T. 2003. Performance analysis of photovoltaic-thermal collector by explicit dynamic model. Solar Energy 75, 143-152.

CHOW, T., HE, W., AND JI, J. 2005. Hybrid photovoltaic-thermosyphon water heating system for residential application. Solar Energy 80, 298-306.

COLLINS, M., AND ZONDAG, H. 2009. Recommended Standard for the Characterization and Monitoring of PV/Thermal Systems. A Report of IEA SHC - Task 35 PV/Thermal Solar Systems, Report DB2. IEA SHC.

CRISTOFARI, C., NOTTON, G., AND CANALETTI, J.-L. 2009. Thermal behavior of a copolymer PV/Th solar system in low flow rate conditions. Solar Energy 83, 11231138.

DEL AMO, A., MARTíneZ, A., BAYOD, A., AND ANTONANZAS, J. 2016. An innovative urban energy system constituted by a photovoltaic/thermal hybrid solar installation: Design, simulation and monitoring. Applied Energy 186.

DIMOUDI, A., AND ANDROUTSOPOULOS, A. 2006. The cooling performance of a radiator based roof component. Solar Energy - SOLAR ENERG 80, 1039-1047.

DUFFIE, J., AND BECKMAN, W. 1991. Solar engineering of thermal processes. Wiley, New York, Chichester. 
DUFFIE, J., AND BECKMAN, W. 2013. Solar Engineering of Thermal Processes. John Wiley \& Sons, Inc, Hoboken, NJ, USA.

DURASOL. Durability of Solar Materials and Systems. https://www.durasol.fr/.

EICKER, U., AND DALIBARD, A. 2011. Photovoltaic-thermal collectors for night radiative cooling of buildings. Solar Energy - SOLAR ENERG 85, 1322-1335.

ERELL, E., AND ETZION, Y. 2000. Radiative cooling of buildings with flat-plate solar collectors. Building and Environment 35, 297-305.

ESTIF COUNTRY REPORTS. Detailed Country Reports.

http://www.estif.org/solarkeymarknew/component/content/article/13-public-area/45country-reports).

ESTIF/SKN. The Solar Keymark Scheme Rules. http://www.estif.org/solarkeymarknew/the-solar-keymark-scheme-rules.

ESTIF/SOLAR KEYMARK LABEL. What is the Solar Keymark? http://www.estif.org/solarkeymarknew/manufacturers/what-is-the-solar-keymark.

EVANS, D., AND FLORSCHUETZ, L. 1977. Cost studies on terrestrial photovoltaic power systems with sunlight concentration. Solar Energy 19, 3, 255-262.

FARMAHINI, M., HEIDARINEJAD, G., AND DELFANI, S. 2010. A two-stage system of nocturnal radiative and indirect evaporative cooling for conditions in Tehran. Energy and Buildings - ENERG BLDG 42, 2131-2138.

Fischer, S., HeidemanN, W., Müller-Steinhagen, H., Perers, B., Bergquist, P., AND HELLSTRÖM, B. 2004. Collector test method under quasi-dynamic conditions according to the European Standard EN 12975-2. Solar Energy 76, 1, 117-123.

FLORSCHUETZ, L. 1979. Extension of the Hottel-Whillier model to the analysis of combined photovoltaic/thermal flat plate collectors. Solar Energy 6, 79-92.

FRAUNHOFER ISE. PVT Normung - Zertifizierung von PVT-Kollektoren.

https://www.ise.fraunhofer.de/de/forschungsprojekte/pvt-normung.html.

FRITZSCHE, U., SCHWEIGER, M., AND REIL, F. 2017. PVT Performance Prediction. In Proceedings of SWC2017/SHC2017. International Solar Energy Society, Freiburg, Germany.

Haller, M., Perers, B., Bales, C., PAaVilainen, J., Dalibard, A., Fischer, S., AND BERTRAM, E. 2013. TRNSYS Type 832. Dynamic Collector Model by Bengt Perers: Updated Input-Output Reference.

HAURANT, P., MÉNÉZO, C., LEON, G., AND DUPEYRAT, P. 2015. Dynamic numerical model of a high efficiency PV-T collector integrated into a domestic hot water system. Solar Energy 111.

HERRANDO, M., MARKIDES, C., AND HELLGARDT, K. 2014. A UK-based assessment of hybrid PV and solar-thermal systems for domestic heating and power: System performance. Applied Energy 122, 288-309.

HERRANDO, M., RAMOS, A., ZABALZA, I., AND MARKIDES, C. 2018. A comprehensive assessment of alternative absorber-exchanger designs for hybrid PVT-water collectors. Applied Energy 235, 1583-1602.

HEYDENREICH, W., MüLleR, B., AND REISE, C. 2008. Describing the World With Three Parameters: A New Approach to PV Module Power Modelling. In Proceedings of the 23rd European Photovoltaic Solar Energy Conference and Exhibition, 27862789.

HOLLANDS, K., UNNY, T., RAITHBY, G., AND KONICEK, L. 1976. Free Convective Heat Transfer Across Inclined Air Layers. Journal of Heat Transfer-transactions of The Asme - J HEAT TRANSFER 98, 189-193.

IAPMO. International Association of Plumbing and Mechanical Officials. https://www.iapmo.org/rt/certification-services/solar-system-certification. 
IEA SHC TASK 44. https://task44.iea-shc.org/publications.

IEA SHC TASK 53. https://task53.iea-shc.org/publications.

IEA SHC TASK 60. https://task60.iea-shc.org/publications

IEC 61730. Photovoltaic (PV) module safety qualification.

https://webstore.iec.ch/publication/25674.

IEC TC 82. International Electrotechnical Commission.

https://www.iec.ch/dyn/www/f?p=103:7:0::FSP_ORG_ID,FSP_LANG_ID:1276,25.

INCROPERA, F., DEWITT, D., BERGMAN, T., AND LAVINE, A. 2007. Fundamentals of Heat and Mass Transfer: Sixth edition.

ISO. 2013. Solar energy -- Solar thermal collectors -- Test methods.

https://www.iso.org/standard/59879.html. Accessed 2019.

ISO. 2017. Solar energy -- Solar thermal collectors -- Test methods.

https://www.iso.org/standard/67978.html. Accessed 2019.

ISO/TC 180. Solar Energy. https://www.iso.org/committee/54018.html.

JONAS, D. 2018a. TRNSYS Type 835 PV model for the coupling with solar thermal absorber and collector models as PVT model. Zenodo.

JONAS, D., LÄMMLE, M., THEIS, D., SCHNEIDER, S., AND FREY, G. 2019. Performance modeling of PVT collectors: Implementation, validation and parameter identification approach using TRNSYS. Solar Energy 193, 51-64.

JONAS, D., THEIS, D., AND FREY, G. 2018b. Implementation and Experimental Validation of a Photovoltaic-Thermal (PVT) Collector Model in TRNSYS. In EuroSun 2018 Conference Proceedings. 12th International Conference on Solar Energy for Buildings and Industry. International Solar Energy Society, Freiburg, Germany.

KALOGIROU, S. 2009. Solar Energy Engineering: Processes and Systems: Second Edition.

KEIZER, C. de, BOTTSE, J., AND JONG, M. de. 2017. PVT Benchmark. An overview of PVTmodules on the European market and the barriers and opportuinties for the Dutch Market.

KRAMER, K., AND HELMERS, H. 2013. The interaction of standards and innovation. Hybrid photovoltaic-thermal collectors. Solar Energy 98, 434-439.

LÄMMLE, M. 2018. Thermal management of PVT collectors. Development and modelling of highly efficient glazed, flat plate PVT collectors with low emissivity coatings and overheating protection. Universität, Freiburg.

LÄMmle, M., Oliva, A., Hermann, M., KRAmer, K., AND KRAMER, W. 2017. PVT collector technologies in solar thermal systems. A systematic assessment of electrical and thermal yields with the novel characteristic temperature approach. Solar Energy 155, 867-879.

LNEG. Research for Sustainability. https://www.Ineg.pt/en/area/energy/renewableenergies/solar-energy/.

LOUWEN, A., WAAL, A. de, SCHROPP, R.E., FAAIJ, A., AND VAN SARK, W. 2017. Comprehensive characterisation and analysis of $\mathrm{PV}$ module performance under real operating conditions. Prog. Photovolt: Res. Appl. 25, 3, 218-232.

LUNDE, P. 1980. Solar Thermal Engineering Space Heating and Hot Water Systems.

MARION, B. 2008. Comparison of predictive models for photovoltaic module performance. In 2008 33rd IEEE Photovoltaic Specialists Conference. IEEE.

NOTTON, G., CRISTOFARI, C., MATTEI, M., AND POGGI, P. 2005. Modelling of a doubleglass photovoltaic module using finite differences. Applied Thermal Engineering $25,2854-2877$. 
PeAn, T., Gennari, L., Olesen, B., AND KAZANCI, O. 2015. Nighttime radiative cooling potential of unglazed and PV/T solar collectors: parametric and experimental analyses. Proceedings of the 8th Mediterranean Congress of Heating, Ventilation and Air-Conditioning (CLIMAMED 2015).

https://backend.orbit.dtu.dk/ws/portalfiles/portal/116282812/Nighttime_radiative_co oling.pdf.

PERERS, B. 2010. An Improved Dynamic Solar Collector Model Including Condensation and Asymmetric Incidence Angle Modifiers. In EuroSun 2010 Conference Proceedings. International Conference on Solar Heating, Cooling and Buildings. ISES Europe; IEA Solar Heating \& Cooling Programme.

PETELA, R. 1961. Exergy of Heat Radiation. PhD Thesis, Faculty of Mechanical Engineering Technology, Silesian Technical University.

POKORNY, N., MATUSKA, T., AND SOUREK, B. 2016. Monitoring of Solar Domestic Hot Water System with Glazed Liquid PVT Collectors. In EuroSun 2016 Conference Proceedings. International Conference on Solar Heating \& Cooling in Buildings. International Solar Energy Society (ISES).

PONS, M. 2012. Exergy analysis of solar collectors, from incident radiation to dissipation. Renewable Energy 47, 194-202.

REJEB, O., DHAOU, H., AND JEMNI, A. 2015. Parameters effect analysis of a photovoltaic thermal collector: Case study for climatic conditions of Monastir, Tunisia. Energy Conversion and Management 89.

RosA-ClOt, M., AND TINA, G. 2017. Submerged and Floating Photovoltaic Systems. Modelling, Design and Case Studies. Elsevier Science, Saint Louis.

SAE. Determination of Effect of Solar Heating. https://www.sae.org/standards/content/j1559_201109/.

SANDNES, B., AND REKSTAD, J. 2002. A photovoltaic/thermal (PV/T) collector with a polymer absorber plate. Experimental study and analytical model. Solar Energy 72, 63-73.

SCHMIDT, C., AND SCHÄFER, A. 2018. Single Source "solar Thermal" Heat Pump for Residential Heat Supply: Performance with an Array of Unglazed PVT Collectors. In Proceedings of EuroSun 2018, A. HÄBERLE, Ed. International Solar Energy Society, Freiburg, Germany, 1-12.

SKOPLAKI, E., AND PALYVOS, J. 2009. On the temperature dependence of photovoltaic module electrical performance: A review of efficiency/power correlations. Solar Energy 83, 5, 614-624.

SPEEDCOLL. http://www.speedcoll.de/.

SPEEDCOLL2. https://www.speedcoll2.de/.

SRCC. Solar Rating \& Certification Corporation. http://solar-rating.org.

TIWARI, A., AND SODHA, M. 2006. Performance evaluation of solar PV/T system: An experimental validation. Solar Energy - SOLAR ENERG 80, 751-759.

TÜV RHEINLAND. 2010. PV-Modul Sicherheitszertifizierung entsprechend IEC 61730:2004 EN 61730:2007. https://www.tuv.com/media/germany/10_industrialservices/downloadsi06/IEC_617 30_Info_20101029.pdf.

WEISS, W., AND SPÖRK-DÜR, M. 2019. Solar Heat Worldwide - 2019 Edition. pp. 2329.

WEISS, W., AND SPÖRK-DÜR, M. 2020. Solar Heat Worldwide - 2020 Edition. pp. 2731.

Zenhäusern, D., BAmBerger, E., AND BAggenstos, A. 2017. PVT Wrap-Up. 
ZHANG, X., ZHAO, X., SMITH, S., XU, J., AND YU, X. 2012. Review of R\&D progress and practical application of the solar photovoltaic/thermal (PV/T) technologies.

Renewable \& Sustainable Energy Reviews - RENEW SUSTAIN ENERGY REV 16.

ZONDAG, H., VRIES, D., HELDEN, W., VAN ZOLINGEN, R., AND VAN STEENHOVEN, A. 2003.

The yield of different combined PV-Thermal collector designs. Solar Energy 74, 253-269.

ZONDAG, H., VRIES, D., VAN HELDEN, W., VAN ZOLINGEN, R., AND VAN STEENHOVEN, A. 2002. The thermal and electrical yield of a PV-Thermal collector. Solar Energy 72 , 113-128. 